\title{
Strong sensitivity of Southern Ocean carbon uptake and nutrient cycling to wind stirring
}

\author{
K. B. Rodgers ${ }^{1}$, O. Aumont ${ }^{2}$, S. E. Mikaloff Fletcher ${ }^{3}$, Y. Plancherel ${ }^{4}$, L. Bopp ${ }^{5}$, C. de Boyer Montégut ${ }^{6}$, D. Iudicone , $^{7}$ \\ R. F. Keeling ${ }^{8}$, G. Madec ${ }^{9,10}$, and R. Wanninkhof ${ }^{11}$ \\ ${ }^{1}$ AOS Program, Princeton University, Princeton, NJ, USA \\ ${ }^{2}$ IRD, Plouzané, France \\ ${ }^{3}$ NIWA, Wellington, New Zealand \\ ${ }^{4}$ Department of Earth Sciences, University of Oxford, Oxford, UK \\ ${ }^{5}$ LSCE, IPSL, CNRS, CEA, UVSQ, Gif-sur-Yvette, France \\ ${ }^{6}$ IFREMER, Centre de Brest, Laboratoire d'Océanographie Spatiale, Plouzané, France \\ ${ }^{7}$ Stazione Zoologica Anton Dohrn, Naples, Italy \\ ${ }^{8}$ Scripps Institute of Oceanography, UCSD, San Diego, CA, USA \\ ${ }^{9}$ LOCEAN, CNRS, IRD, UPMC, MNHN, IPSL, Paris, France \\ ${ }^{10}$ National Oceanography Centre, Southampton, UK \\ ${ }^{11}$ NOAA-AOML, Miami, FL, USA
}

Correspondence to: K. B. Rodgers (krodgers@ princeton.edu)

Received: 28 July 2013 - Published in Biogeosciences Discuss.: 13 September 2013

Revised: 13 June 2014 - Accepted: 19 June 2014 - Published: 1 August 2014

\begin{abstract}
Here we test the hypothesis that winds have an important role in determining the rate of exchange of $\mathrm{CO}_{2}$ between the atmosphere and ocean through wind stirring over the Southern Ocean. This is tested with a sensitivity study using an ad hoc parameterization of wind stirring in an ocean carbon cycle model, where the objective is to identify the way in which perturbations to the vertical density structure of the planetary boundary in the ocean impacts the carbon cycle and ocean biogeochemistry.

Wind stirring leads to reduced uptake of $\mathrm{CO}_{2}$ by the Southern Ocean over the period 2000-2006, with a relative reduction with wind stirring on the order of $0.9 \mathrm{Pg} \mathrm{C} \mathrm{yr}^{-1}$ over the region south of $45^{\circ} \mathrm{S}$. This impacts not only the mean carbon uptake, but also the phasing of the seasonal cycle of carbon and other ocean biogeochemical tracers. Enhanced wind stirring delays the seasonal onset of stratification, and this has large impacts on both entrainment and the biological pump. It is also found that there is a strong reduction on the order of $25-30 \%$ in the concentrations of $\mathrm{NO}_{3}$ exported in Subantarctic Mode Water (SAMW) to wind stirring. This finds expression not only locally over the Southern Ocean, but also over larger scales through the impact on advected nutri-
\end{abstract}

ents. In summary, the large sensitivity identified with the ad hoc wind stirring parameterization offers support for the importance of wind stirring for global ocean biogeochemistry through its impact over the Southern Ocean.

\section{Introduction}

Ocean interior properties over much of the global domain are largely set by late-winter mixed-layer characteristics, as these are the characteristics passed to the interior during restratification in early spring (Stommel, 1979). For this reason, ocean modelers have long been interested in improving ocean mixing parameterizations that ameliorate the representation of winter mixed-layer depths, and thereby ventilation in their models. In light of the advent of sophisticated prognostic biogeochemical modeling, there is a growing realization that a skillful representation of summer mixed-layer depths is also important to correctly simulate the effect of light limitation and the role this plays in biological productivity. To date, the biogeochemical consequences of uncertainties related to summer mixing processes has not been 
thoroughly explored. Our main focus is to conduct such an analysis for the case of carbon over the Southern Ocean, but also to give more general consideration to other tracers related to ocean biogeochemistry. This is considered within the context of the full seasonal cycle over the Southern Ocean, and the implications for trends in carbon uptake are explored.

There is widespread interest in understanding the way in which surface atmospheric winds contribute to the partitioning of $\mathrm{CO}_{2}$ between the oceanic and atmospheric reservoirs. Surface winds may impact the ocean carbon cycle in three ways:

1. through wind-driven microturbulence at the air-sea interface that controls the gas exchange velocity;

2. through wind-driven meridional overturning and water mass transformations, as impacted by large-scale interactions with the atmosphere, including the net transfer of momentum and buoyancy to the ocean over large scales;

3. through wind-driven stirring and the transfer of energy over the planetary boundary layer of the ocean (within the mixed layer and below) through shear-induced turbulence.

The issue of air-sea gas exchange has been and continues to be the focus of extensive research, including the development of gas exchange parameterizations for use with models (Wanninkhof, 1992; see Wanninkhof et al., 2009 for a more extensive overview). The magnitude of the derived piston velocity exerts a major control on seasonal variations in air-sea $\mathrm{CO}_{2}$ fluxes but has less influence on the long-term uptake of $\mathrm{CO}_{2}$, which is mainly controlled by circulation and mixing within the ocean (Bolin and Eriksson, 1958; Sarmiento et al., 1992). Models show instead much greater sensitivities to changes in the physical transport and mixing parameterizations, particularly in the Southern Ocean (Mignone et al., 2006). A number of studies (Wyrtki, 1961; Toggweiler and Samuels, 1993; Gnanadesikan, 1999) have established a central role for winds over the Southern Ocean in determining the overturning circulation of the global ocean and therefore ocean carbon cycling. More recent work with eddypermitting models (Hallberg and Gnanadesikan, 2006) and observationally based analyses (Böning et al., 2008) has also drawn attention to the importance of geostrophic turbulence (ocean eddies) in modulating the response of the overturning circulation to perturbations in surface winds. The study of the implications of geostrophic turbulence for the Southern Ocean carbon cycle is an active area of research (Ito et al., 2010).

The issue of shear-induced turbulence and wind stirring has received far less attention to date and it is the focus of this study. The mechanical input of energy from the winds into the upper ocean and the subsequent dissipation through shear-induced mixing may play a role in determining summer mixed-layer depths. This is likely to be of particular importance over the Southern Ocean, where $50 \mathrm{~m}$ mixed-layer depths are sustained through summer under the influence of the maximum westerlies between $50-60^{\circ} \mathrm{S}$, with no consensus yet on the mechanisms that sustain this phenomenon. The two main mechanisms for wind stirring over this region may be expected to be upper-ocean near-inertial oscillations (Jochum et al., 2013) and ocean swells and waves (Qiao et al., 2004; Huang et al., 2012; Huang and Qiao, 2010). The relative importance of these mechanisms remains unknown. Importantly, these two mechanisms result in a net erosion of stratification, and they add potential energy to the upper ocean. As such, their impact in stratification stands in marked contrast to that of mesoscale eddies, which remove potential energy from the ocean. Thus, shear-induced turbulence and geostrophic turbulence should have opposing effects on climatological mixed-layer depths averaged over particular seasons.

The current generation of coupled and ocean-only models tends to exhibit shallow summer mixed-layer biases over the Southern Ocean (Huang et al., 2012) and excessive stratification at the base of the mixed layer. It has been shown that Southern Ocean winds are typically too weak and too far equatorward in coupled models (Fyfe and Saenko, 2006), which may explain some of the mixed-layer bias in these models. Nonetheless, Southern Ocean summer mixed layers are also too shallow in ocean-only models forced with observed atmospheric winds and buoyancy fluxes, indicating that important physical processes responsible for upperocean mixing are missing from current model formulations.

The degree to which the shallow summer mixed-layer bias affects the ability of models to correctly simulate uptake and storage patterns of carbon and heat is not clear but different arguments suggest it is not negligible. First, the depth of the actively mixed layer in the upper ocean defines the total light available to phytoplankton (de Baar et al., 2005) and thus affects models' ability to correctly simulate the biological response to iron supply in the Southern Ocean, inducing an error in simulations of the biological pump. More generally, the misrepresentation of seasonal mixed-layer dynamics affects the overall biogeochemical landscape in the Southern Ocean (Marinov et al., 2006). Since the Southern Ocean exports nutrients that fuel a large part of low latitude productivity (Sarmiento et al., 2004), these regional errors that affect the processes determining the distribution and seasonal cycling of nutrients in the Southern Ocean can have long-range effects.

Furthermore, inasmuch as Southern Ocean storminess is expected to increase in response to increasing anthropogenic greenhouse gas emissions by $\sim 20 \%$ by the end of the 21 st century (Wu et al., 2010, and references therein), an accurate model representation of the effect of winds on ocean stratification is necessary in order to faithfully simulate the consequences of changes in the intensity or frequency of storms on 
the physical environment, on local and global biogeochemistry and on the overall ability of the Southern Ocean to maintain its role as a region of intense heat and carbon uptake.

Here, an ad hoc wind stirring parameterization that allows energy from the winds to be input into the region below the base of the mixed layer was added to a global ocean biogeochemistry model in order to correct for the summer mixed-layer bias in the model and better represent summer mixed-layer dynamics. By contrasting two model runs, one with the ad hoc parameterization and a control run without, we evaluate the sensitivity of oceanic $\mathrm{CO}_{2}$ uptake and ocean biogeochemistry to the imposed change in wind stirring. We show that accounting for the additional effect of wind stirring greatly reduces contemporary carbon uptake in the Southern Ocean. The reasons for this effect and its consequences on the geographical distribution of carbon and oxygen fluxes, mixed-layer depth, stratification, chlorophyll, and nutrients are investigated further, highlighting the importance of wind stirring on the seasonal cycle of these properties. Finally, given protected future changes in the intensity and frequency of storms (Wu et al., 2010), we consider our two simulations with and without wind stirring as representative of two hypothetical climate states, one with low and one with high storminess. Furthermore, we question if increased storminess, as simulated by the added ad hoc parameterization, has an effect on atmospheric $\mathrm{CO}_{2}$ levels by impacting the oceanic carbon sink. Because terrestrial processes contribute to atmospheric $\mathrm{CO}_{2}$ variability, we rely here on the concept of atmospheric potential oxygen (APO) (Keeling and Schertz, 1992; Stephens et al., 1998), a tracer that is conserved with respect to the terrestrial biosphere and primarily reflects ocean fluxes. We show that a change in wind stirring manifests itself as a shift in the phasing of the seasonal APO cycle in the sub-polar Southern Hemisphere. If large enough, this shift should be detectable from the existing network of atmospheric monitoring stations.

\section{Methods}

\subsection{General model description and experimental design}

The experiments are performed with the NEMO-PISCES model (Madec et al., 1998; Aumont and Bopp, 2006) in the global ORCA2 configuration of NEMO Version 3.2. Horizontal resolution is $2^{\circ}$, increasing to approximately $1^{\circ}$ over the Southern Ocean. Mesoscale eddies are parameterized with the scheme of Gent and McWilliams (1990). Vertical mixing in NEMO is achieved using the turbulence kinetic energy (TKE) parameterization of Blanke and Delecluse (1993), and the TKE parameterization includes a Langmuir cell parameterization (Axell, 2002).

The representation of light limitation in the evolution of the PISCES model used here has been modified relative to the version of PISCES described in Aumont and Bopp
(2006). The influence of light limitation on the growth rate of nanophytoplankton $\left(\mu^{\mathrm{P}}\right)$ is modeled in this version of PISCES using a modified version of the Geider et al. (1998) formulation in which the nutrient co-limitation term and the dependence on temperature were removed in accordance with the findings by Li et al. (2010):

$\mu^{\mathrm{P}}=\mu_{\max } \cdot\left(1-\exp \left(-\alpha \cdot \frac{\mathrm{Chl}}{\mathrm{C}} \cdot \frac{\text { light }}{P_{\max }}\right)\right)$,

where $P_{\max }$ is a constant that does not depend on temperature and nutrient limitation. Two simulations, WSTIR and CNTRL, are considered. WSTIR and CNTRL only differ in that an ad hoc parameterization (described below) for the effect of wind stirring as a component of vertical mixing is used in WSTIR but not in CNTRL. Other than that, WSTIR and CNTRL have identical wind stresses and surface buoyancy boundary conditions, identical horizontal and vertical resolution, and identical biogeochemical and physical parameter settings. It is important to emphasize that the same parameterization of gas exchange (Wanninkhof, 1992) with precisely the same wind speeds is used for gas exchange for both WSTIR and CNTRL.

The initial state for temperature and salinity was taken from the World Ocean Atlas 2009 (WOA09) (Locarnini et al., 2010; Antonov et al., 2010), and the initial state for biogeochemistry was taken from a 5000-year pre-industrial spin-up of NEMO-PISCES. At the time of initialization for this study, the ocean was treated as being in a state of no motion. This initial model state nominally corresponds to year 1864. The model was then forced at its upper surface using the DRAKKAR forcing set \#4.1, or DFS4.1 (Brodeau et al., 2010), which is derived from the ERA-40 reanalysis product (Uppala et al., 2005) and has a temporal resolution of six hours. DFS4.1 spans years 1958-2006. The model was looped twice through repeating full DFS4.1 forcing fields cycles to reach year 1957 with atmospheric $\mathrm{CO}_{2}$ concentrations increasing over this time. The two parallel simulations WSTIR and CNTRL were started in year 1958 as described above. As such, the same transient in atmospheric $\mathrm{CO}_{2}$ boundary conditions is present in both simulations.

The question arises as to whether the time interval over which we considered the sensitivity to wind stirring (19582006) is of sufficient duration to distinguish between spurious signals associated with adjustments and the steady-state response of the Southern Ocean carbon cycle to our ad hoc wind stirring parameterization. Importantly, we are interested in both the adjustment period and the steady-state response of the system to the applied perturbation.

\subsection{Ad hoc parameterization of wind stirring}

Vertical mixing parameterizations commonly used in ocean general circulation models tend to produce mixed-layer depths that are too shallow during summer months; this bias is particularly acute over the Southern Ocean. To overcome 
this systematic bias, an ad hoc parameterization was introduced into the TKE vertical mixing scheme of Blanke and Delecluse (1993) within NEMO. The parameterization presented here is not derived from theoretical considerations, but rather is meant to account for observed processes that affect the density structure of the ocean's planetary boundary layer that are not explicitly captured by default in the TKE scheme. These processes are near-inertial oscillations (Jochum et al., 2013) and ocean swells and waves (Qiao et al., 2004; Huang et al., 2012; Huang and Qiao, 2010).

First, a vertical mixing-length scale $h_{\tau}$ (Fig. 1) is computed as a function of latitude ( $\varphi$, units of latitude):

$h_{\tau}=\max (0.5, \min (30,45 \cdot \sin (\varphi))) \forall \varphi \geq 0$,

$h_{\tau}=\max (0.5,2 \cdot \min (30,45 \cdot \sin (\varphi))) \forall \varphi<0$.

Values for $h_{\tau}$ vary from $0.5 \mathrm{~m}$ at the Equator to a maximum of $30 \mathrm{~m}$ in the high latitudes of the Northern Hemisphere and $60 \mathrm{~m}$ in the Southern Ocean. The above definition of mixing length was tuned to achieve summer mixed-layer depths consistent with observations and that are also consistent with the wave-induced mixing-length scales reported by Qiao et al. (2004). During the tuning phase, vertical mixinglengths spanning $30 \mathrm{~m}$ to $70 \mathrm{~m}$ were tried over the Southern Ocean, with $60 \mathrm{~m}$ providing the best match against observational constraints.

The kinetic energy input to the ocean $(S)$ imposed by the winds in the form of near-inertial oscillations, swell and waves is parameterized as follows:

$S=\varepsilon_{i} \cdot \exp \left(\frac{-z}{h_{\tau}}\right) \cdot\left(1-f_{i}\right)$,

where $z$ is the depth and $\varepsilon_{i}$ (adjusted here to 0.07) is the fraction of the kinetic energy imposed by wind stress as computed by the traditional TKE implementation of Blanke and Delecluse (1993) $\left(\mathrm{TKE}_{\mathrm{BD} 93}\right)$. This value is similar to the scaling factor $\alpha=0.05$ used by Jochum et al. (2013) to parameterize the input of kinetic energy into the ocean due to near-inertial oscillations. The depth structure of the energy input function in the ocean interior is modeled using an exponential function that depends on the mixing-length $h_{\tau}$. This is modulated by the fractional sea-ice concentration $\left(f_{i}\right)$ as the influence of wind stress below sea ice is small. The overall kinetic energy input in WSTIR is obtained by summing the traditional TKE input obtained by the Blanke and Delecluse (1993) scheme and S:

$\mathrm{TKE}_{\mathrm{WSTIR}}=\mathrm{TKE}_{\mathrm{BD} 93}+S$.

As the magnitude of $\mathrm{TKE}_{\mathrm{BD} 93}$ is much greater than $S$ in the mixed layer, the contribution of $S$ is relatively small there. The relative influence of $S$ is strongest just below the mixed layer at times and locations where the mixing-length $h_{\tau}$ is greater than the mixed-layer depth generated by $\mathrm{TKE}_{\mathrm{BD} 93}$. In these locations, $S$ erodes the stratification, thus contributing to deepening of the mixed layer.

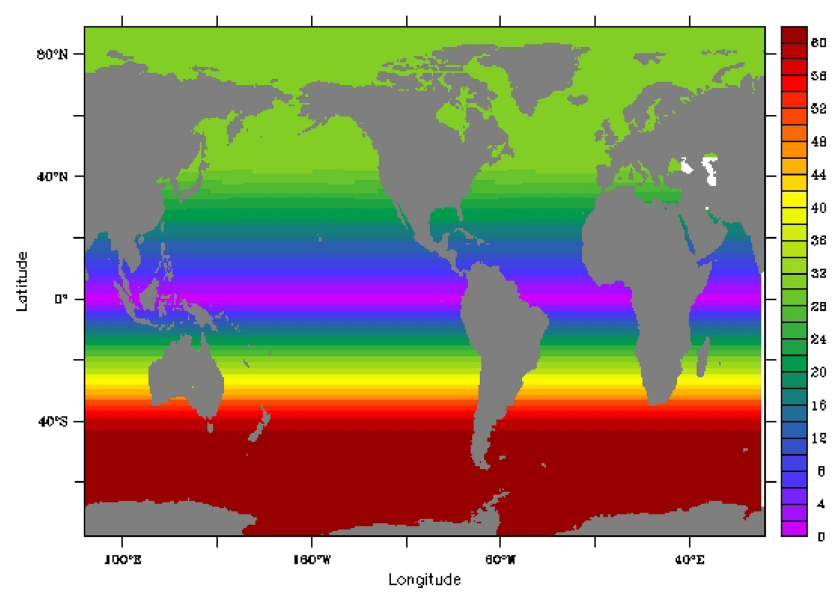

Figure 1. The mixing-length scale over which the ad hoc wind stirring parameterization is prescribed to act in the WSTIR simulation, in units of meters.

A number of observational products are available that provide consistent views of seasonal variations in mixed-layer depths over the Southern Ocean (de Boyer Montégut et al., 2004; Dong et al., 2008; Huang et al., 2012). Here we choose to use a new 2013 update of the climatology of de Boyer Montégut et al. (2004), which has benefited from the large increase in Argo measurements over the last decade. The original release of this product, and the 2008 update, used a density deviation from the surface of $0.03 \mathrm{~kg} \mathrm{~m}^{-3}$ to characterize the base of the mixed layer. However, the increased quantity of Argo measurements now allows a density criterion of $0.01 \mathrm{~kg} \mathrm{~m}^{-3}$ to be used, by overcoming signal-to-noise issues, and that is what we will use here. Given the relatively weak stratification of the Southern Ocean, this smaller criterion is appropriate for our analysis of seasonal variability in mixed-layer depths. Nevertheless, we will also consider the sensitivity of Southern Ocean mixed-layer depth (MLD) variations to the amplitude of this threshold.

\subsection{Atmospheric potential oxygen: definition, simulation and observations}

Observed variations in atmospheric $\mathrm{CO}_{2}$ concentrations over seasonal to decadal timescales are difficult to interpret in terms of ocean processes as only a small fraction of the $\mathrm{CO}_{2}$ variability actually comes from the ocean. A much larger fraction of the variability in $\mathrm{CO}_{2}$ is caused by exchanges with the land biosphere; this is true even in regions remote from direct land biospheric influences, such as the high latitudes of the Southern Hemisphere (e.g., Stephens et al., 2013). An atmospheric constraint on oceanic processes can be derived by combining measurements of atmospheric $\mathrm{CO}_{2}$ and $\mathrm{O}_{2} / \mathrm{N}_{2}$ ratios to compute atmospheric potential oxygen (APO). APO is defined as follows:

$$
\mathrm{APO}=\delta\left(\mathrm{O}_{2} / \mathrm{N}_{2}\right)+1.1 \cdot 4.8 \cdot \mathrm{CO}_{2} .
$$


In this expression $\delta \mathrm{O}_{2} / \mathrm{N}_{2}$ ) is the ratio of $\mathrm{O}_{2}$ to $\mathrm{N}_{2}$ relative to the ratio in standard air and is referred to as having units of per meg (equivalent to per million). The emissions ratio of $\mathrm{CO}_{2}$ to $\mathrm{O}_{2}$ from terrestrial processes is typically 1.1 with only small deviations (Severinghaus et al., 2001). Since $\mathrm{O}_{2}$ comprises $20.94 \%$ of the atmosphere, a conversion factor of $1 / 0.2094=4.8$ can be used to convert $\mathrm{CO}_{2}$ from units of ppm to units of per meg. APO is conserved with respect to the terrestrial biosphere, which causes compensating variations in $\delta\left(\mathrm{O}_{2} / \mathrm{N}_{2}\right)$ and $\mathrm{CO}_{2}$. Much of the variability in APO over seasonal and shorter time scales reflects ocean fluxes (Keeling and Shertz, 1992; Stephens et al., 1998). In addition, while physical and biological processes in the ocean often have opposing effects on $\mathrm{CO}_{2}$, damping the atmospheric signal of these processes, they typically have additive effects on $\mathrm{O}_{2} / \mathrm{N}_{2}$. For example, summertime $\mathrm{CO}_{2}$ uptake represents a balance of biologically driven uptake and thermally driven outgassing of $\mathrm{CO}_{2}$, while biological and thermal processes both lead to $\mathrm{O}_{2}$ uptake.

High-frequency APO data are available down to the timescale of a week. Such high-frequency data are not available for $p \mathrm{CO}_{2}$, for which there is also a well-known lack of both winter and summer measurements. APO also stands in contrast to remotely sensed ocean color products, whose temporal sampling can be strongly affected by cloud cover. Although APO data are only available for specific sites, these are atmospheric observations and they represent large wellmixed air masses that integrate surface processes over large parts of the Southern Ocean. The APO data from the Scripps network used in this study are described in detail in Hamme and Keeling (2008) and Keeling and Manning (2013).

In order to investigate the effect of the wind stirring parameterization on APO, daily mean air-sea fluxes of $\mathrm{O}_{2}, \mathrm{CO}_{2}$, and heat from the WSTIR and CNTRL ocean simulations are used as lower boundary conditions in a three-dimensional atmospheric transport model, Tracer Model Version 3 (TM3) (Heimann and Körner, 2003). Since the air-sea flux of $\mathrm{N}_{2}$ is not modeled explicitly in NEMO-PISCES but is needed to simulate APO, the air-sea fluxes of $\mathrm{N}_{2}$ are calculated from the heat fluxes following the formulation of Keeling and Peng (1995) using the temperature-dependent $\mathrm{N}_{2}$ solubility of Weiss (1970).

TM3 is an offline model driven by the National Centers for Environmental Prediction (NCEP) reanalysis winds (Kalnay et al., 1996). The fine-grid version used here has a resolution of $\sim 3.8^{\circ} \times 5^{\circ}$ with 19 vertical levels. TM3 is well documented and has been included in many model intercomparisons studies (e.g., Denning et al., 1999; Gurney et al., 2003), and compares well with other models when evaluated against aircraft data (Stephens et al., 2007). TM3 was run from 1990 to 2005 but only years 1994-2005 are analyzed to account for spin-up effects of the atmospheric model.

It is important to consider whether the inconsistency between the ocean forcing reanalysis product (DRAKKAR) and the atmospheric transport fields used for APO (NCEP) can be expected to impact our scientific results or interpretations. Our primary interest with these simulations is to use the seasonal behavior of APO to evaluate the two versions of the NEMO model. Blaine (2005) compared APO simulations from a suite of ten different atmospheric transport models using the same air-sea fluxes as boundary conditions, with some of the transport models driven by NCEP and some driven by ERA-40. For the high latitude Southern Ocean stations, the atmospheric transport models simulated slightly different seasonal amplitudes, but were in good agreement regarding the seasonal cycle.

We also account for small variations in APO caused by fossil fuel burning. Fossil fuel emissions were distributed spatially according to the 1995 Carbon Dioxide Information Analysis Center (CDIAC) fossil fuel emissions map (Marland et al., 1998). The spatial distribution was then scaled for emissions for specific years (Boden et al., 2012). $\mathrm{O}_{2}$ consumed by fossil fuels was calculated simply by using a simple combustion ratio of 1.4 moles of $\mathrm{O}_{2}$ for every mole of $\mathrm{CO}_{2}$ (Keeling et al., 1998; Marland et al., 2003). Spatial and temporal variations of the $\mathrm{O}_{2} / \mathrm{CO}_{2}$ combustion ratio arising from differences in fuel types are not considered, but this omission is unlikely to be problematic for our analysis and interpretation of the seasonal APO signal.

\section{Results}

\subsection{Wind stirring, mixed-layer depths, and stratification}

The 2014 update of the mixed-layer depth product of de Boyer Montégut et al. (2004) shows austral summer mixed layer depth on the order of $50 \mathrm{~m}$ (January) and austral winter mixed layer depth on the order of $150 \mathrm{~m}$ (October) in the latitude band $50-60^{\circ} \mathrm{S}$, the region under the maximum westerlies (Fig. 2a, solid black line in Fig. 2d). Austral summer mixed-layer depths for CNTRL are consistently too shallow in the Southern Ocean (Fig. 2b), with summer mixed layer depths having maximum values on the order of only $20 \mathrm{~m}$ (Fig. 2d). Austral summer mixed-layer depths for WSTIR are twice as deep as those for CNTRL (Fig. 2c and red line in Fig. 2d), and in better agreement with summer observations, as intended with the application of the ad hoc mixing parameterization.

Austral winter mixed-layer depths for WSTIR are larger than observed values however $(260 \mathrm{~m}$, red line in Fig. 2d). Input of wind energy at depth in summer (according to Eqs. 13 ) reduces the stratification just below the depth of the mixed layer resulting from $\mathrm{TKE}_{\mathrm{BD} 93}$. As a consequence, during fall and winter as the ocean de-stratifies, buoyancy forcing needs to do less work against the relatively weakened submixed-layer stratification. Furthermore, the ad hoc parameterization was used throughout the year. The excessive winter mixed-layer depth in WSTIR indicates that the current 
(a)

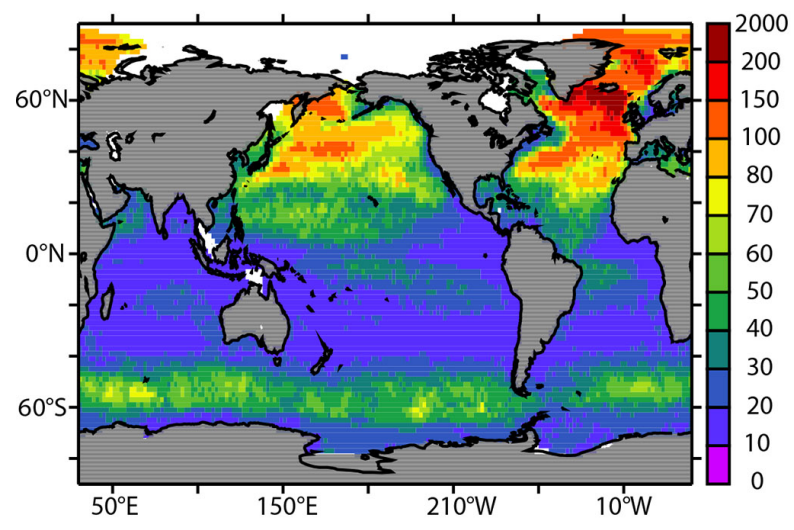

(c)

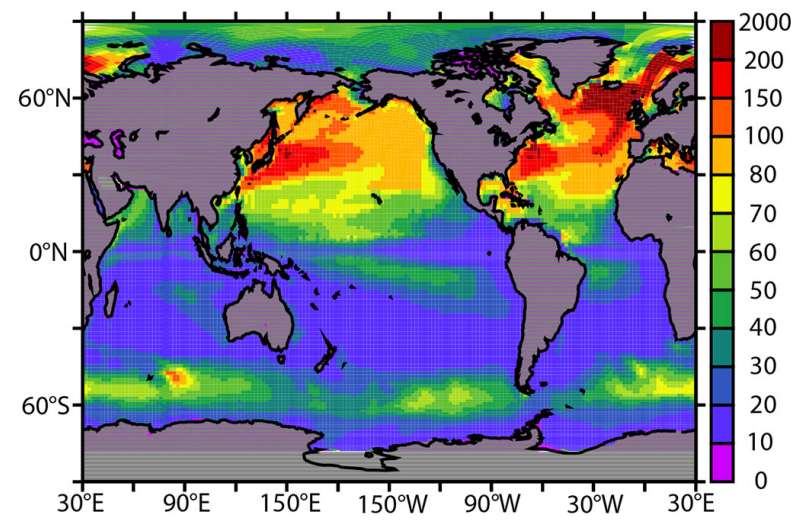

(b)

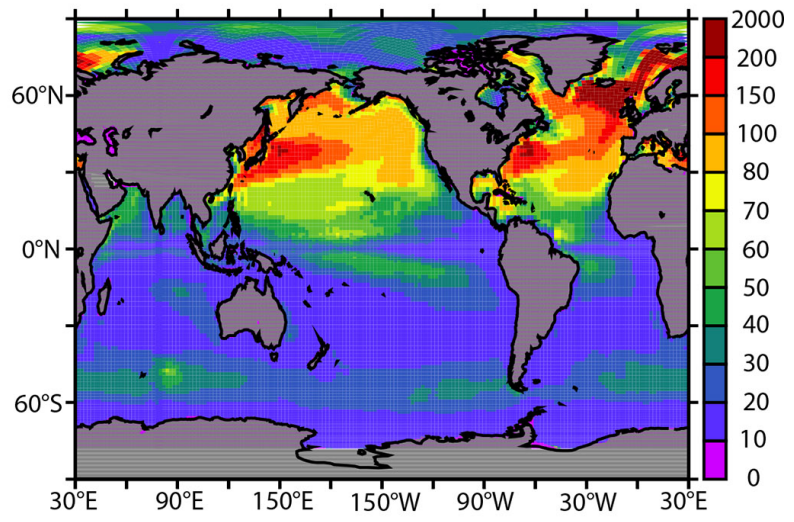

(d)

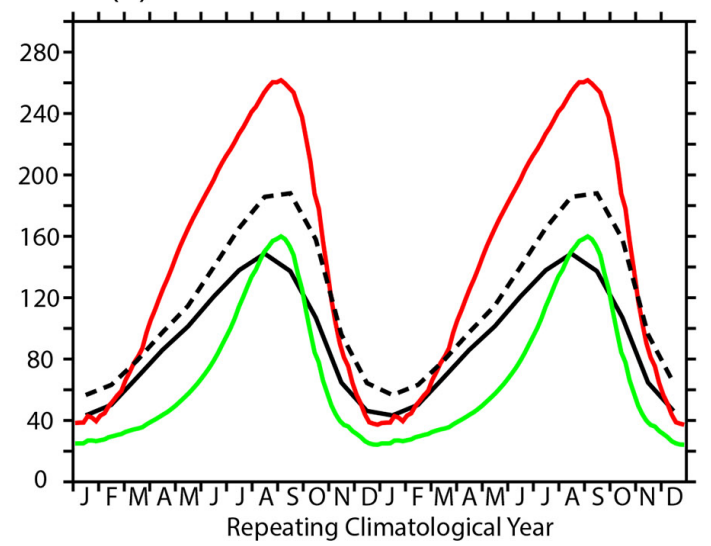

Figure 2. Mixed-layer depth (MLD) comparison; in all panels, units are meters. Updated product of de Boyer Montégut et al. (2004) averaged over austral summer (December-February, or DJF) using a $\Delta \sigma_{0}=0.01$ criterion (a). CNTRL averaged over DJF for climatology constructed over 2000-2006 using a $\Delta \sigma_{0}=0.01$ criterion (b). WSTIR averaged over DJF for climatology constructed over 2000-2006 using a $\Delta \sigma_{0}=0.01$ criterion (c). Time series: evolution of MLD averaged over 50-60 $\mathrm{S}$ for data product of de Boyer Montégut et al. (2004) using a $\Delta \sigma_{0}=0.01$ criterion (solid black), $\Delta \sigma_{0}=0.03$ (dashed black), WSTIR (red), and CNTRL (green) (d).

ad hoc implementation, although invoked to help in summer, also has indirect negative consequences in winter. The improved summer mixed-layer depths for WSTIR relative to CNTRL are clearly the consequence of tuning, but the fact that the WSTIR case is in better agreement with observations is relevant for our later considerations of the biogeochemical sensitivity.

It is also of interest to consider the phase of the seasonal cycle averaged over the same band, namely $50-60^{\circ} \mathrm{S}$. In particular, we are interested in identifying whether the ad hoc parameterization impacts the timing of restratification. The mixed layer in CNTRL reaches $60 \mathrm{~m}$ on 30 October, about three months after the winter maximum in August. The $60 \mathrm{~m}$ threshold is crossed on 4 December in the WSTIR simulation, which is five weeks after the CNTRL case and more than four months after peak winter mixed layers. Although the winter mixed layer is too deep and the summer mixed layer is too shallow in WSTIR, there is a period during the re-stratification phase after winter (October) where WSTIRsimulated mixed-layer depth is more consistent with the observed timing of stratification. It is important to emphasize here, however, that our scientific interest is in the phasing of the seasonal cycle, rather than claiming that the WSTIR simulation represents a state estimate. The implication of this is that mechanical wind stirring does not impact only mean mixed-layer depths. It also contributes to setting the phase of the destratification and restratification cycle, acting in concert with the seasonal cycle of buoyancy forcing.

Before turning our attention to the sensitivity of the vertical structure of stratification between WSTIR and CNTRL in Fig. 3, we first give consideration to the sensitivity of the inferred seasonal cycle of mixed-layer depth from the data to the amplitude of the density threshold criterion. In Fig. 2d, the mixed-layer depth from observations using $\Delta \sigma_{0}=0.03$ is shown as a dashed black line; this should be compared to that for $\Delta \sigma_{0}=0.01$ shown with a solid black line. Note 
(a)

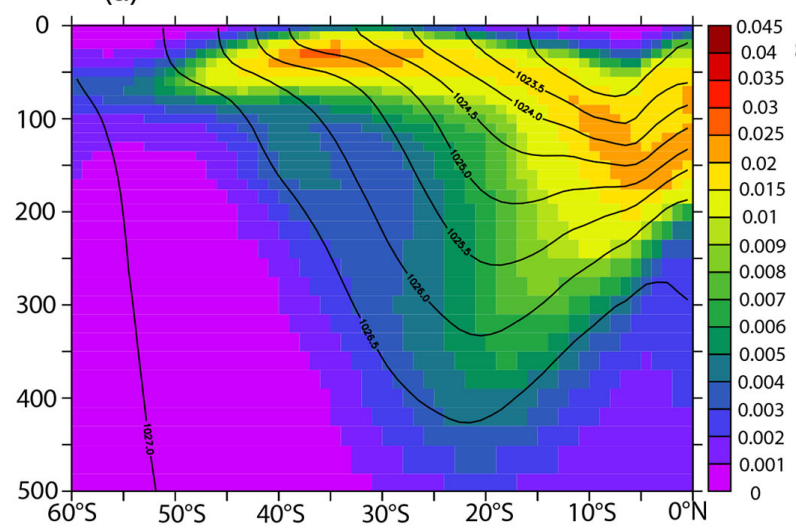

(b)

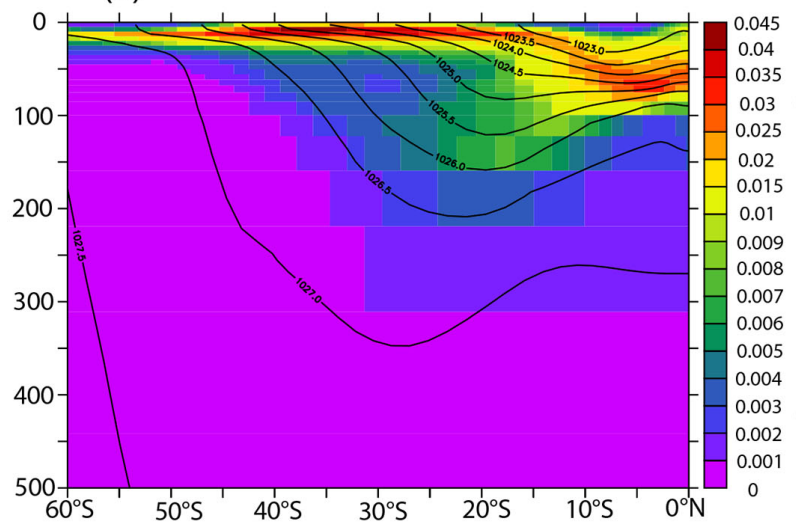

(c)

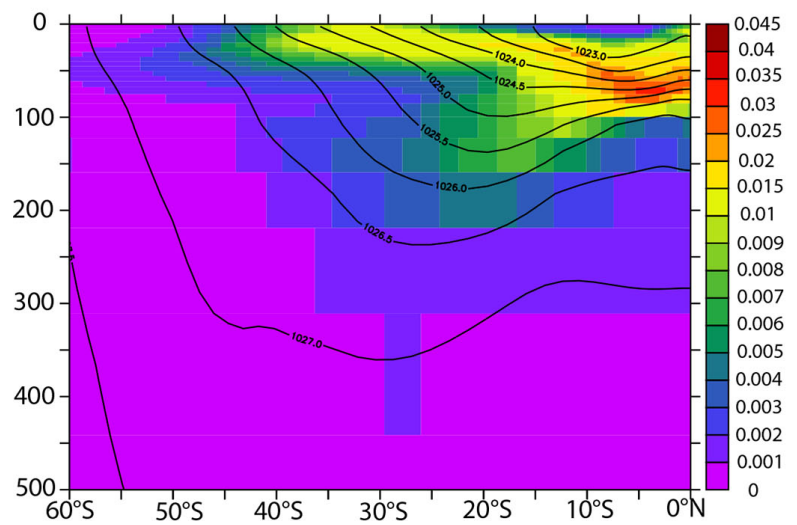

(d)

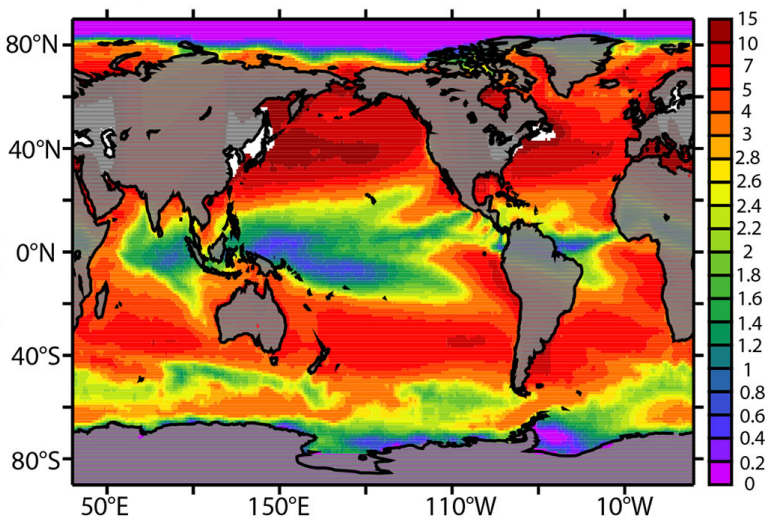

(e)

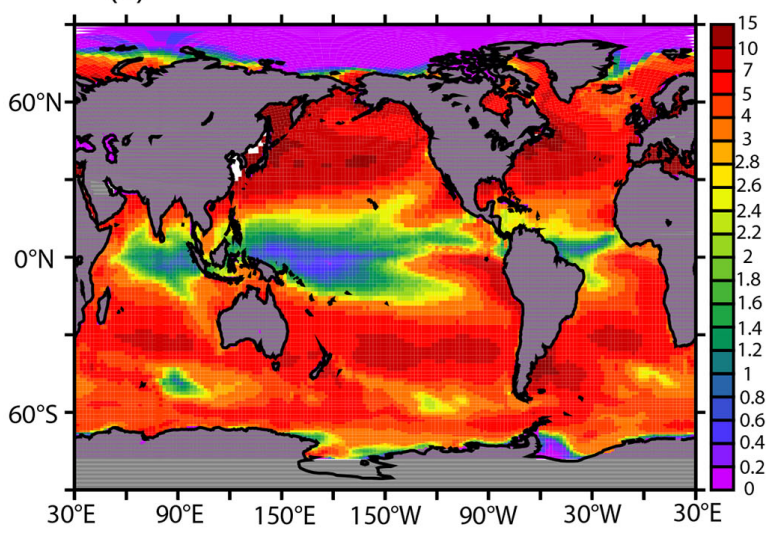

(f)

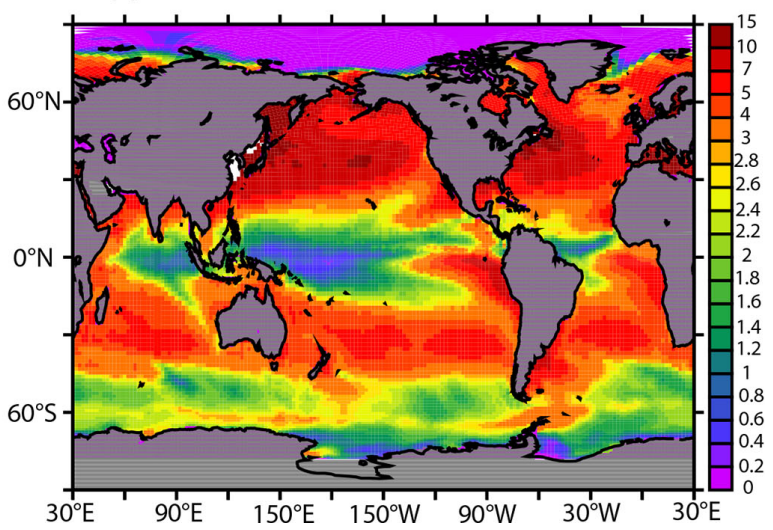

Figure 3. The stratification $\mathrm{d} \rho_{0} / \mathrm{d} z$ (colors) is shown, averaged over the central South Pacific $\left(160^{\circ} \mathrm{E}-100^{\circ} \mathrm{W}\right)$, for (a) the ARGO-extended data product of de Boyer Montégut et al. (2004), (b) CNTRL, and (c) WSTIR. For each case, potential density contours are overlaid. Also shown is the amplitude of the seasonal cycle of sea surface temperature (SST) $\left({ }^{\circ} \mathrm{C}\right)$ from (d) the product of Reynolds and Smith (1994) including remote sensing data, (e) for the climatology of the CNTRL run over 2000-2006, and (f) for the climatology of the WSTIR run considered over 2000-2006.

that the $\Delta \sigma_{0}=0.03$ corresponds to what was originally published by de Boyer Montegut et al. (2004). There are large differences not only in summer, where the contrast is between $50 \mathrm{~m}\left(\Delta \sigma_{0}=0.01\right)$ and $65 \mathrm{~m}\left(\Delta \sigma_{0}=0.03\right)$, but also in winter, where the contrast is between $150 \mathrm{~m}\left(\Delta \sigma_{0}=0.01\right)$ and $200 \mathrm{~m}\left(\Delta \sigma_{0}=0.03\right)$. This sensitivity is consistent with what was shown by Holte and Talley (2009).

Figure 3 compares zonally averaged (South Pacific sector, $160^{\circ} \mathrm{E}$ to $100^{\circ} \mathrm{W}$ ) meridional sections of stratification $\left(\mathrm{d} \rho_{0} / \mathrm{d} z\right)$ taken from CNTRL and WSTIR and the stratification derived from the January distribution of density 
from the Argo-derived climatology of Roemmich and Gilson (2009). The Argo-derived data product (Fig. 3a) reveals a relatively weak stratification over the Southern Ocean. The stratification is significantly stronger than the observations for the CNTRL case (Fig. 3b) over the Southern Ocean, but relatively weak for the WSTIR case (Fig. 3c). The stratification maximum is shallower for WSTIR than it is for observations over the Southern Ocean, but is shallower still for CNTRL.

We consider next the amplitude of the seasonal cycle of sea surface temperature (SST), considered for a climatology constructed for years 2000-2006. This is considered first in Fig. 3d for the observational product derived using the method of Reynolds and Smith (1994), which includes remote sensing information. Over large parts of the Southern Ocean, the amplitude of the seasonal cycle of SST is on the order of $2{ }^{\circ} \mathrm{C}$. The distribution shown for the CNTRL run in Fig. 3e exhibits seasonal variability over the Southern Ocean that is much too large. For the WSTIR run shown in Fig. 3f, it can be seen that the seasonal amplitude of SST is much smaller than for CNTRL, with variations on the order of $2{ }^{\circ} \mathrm{C}$ seen over much of the Southern Ocean. The seasonal amplitude of SST in the WSTIR run is slightly smaller than that in the observational product in Fig. 3d, but it is generally in better agreement with the observational product than the CNTRL run. These large differences between WSTIR and CNTRL exist despite the fact that both runs have an effective relaxation of SST to the same air temperature field in the bulk formulas used for gas exchange. The tendency of SST in CNTRL to be too warm in summer is consistent with the overstratification seen in Fig. 3b, as well as a self-reinforcing diminished heat capacity associated with the strong shallow bias in summertime mixed layer depth seen in Fig. 2b. Interestingly, the amplitude of the seasonal cycle of heat content (not shown) is larger for the WSTIR case than for the CNTRL case over the Southern Ocean, in contrast to what is found for SST.

\subsection{Influence of enhanced wind stirring on carbon uptake}

We next consider the decadal-timescale differences in the air-sea exchange of carbon for the two model runs. Southern Ocean carbon uptake (integrated over the region south of $45^{\circ} \mathrm{S}$ ) is greater for CNTRL than for WSTIR (Fig. 4), with this difference increasing over time. In the discussion here, we ignore the original 5-year adjustment period for the original shock starting in 1958. This offset and the different evolution of these two simulations have profound implications for the role of the Southern Ocean in the global carbon cycle. The WSTIR run results in carbon outgassing over the Southern Ocean while the CNTRL run simulates carbon uptake throughout the 1965-2006 period. The outgassing in WSTIR decreases slightly at a rate

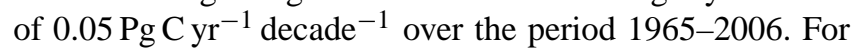

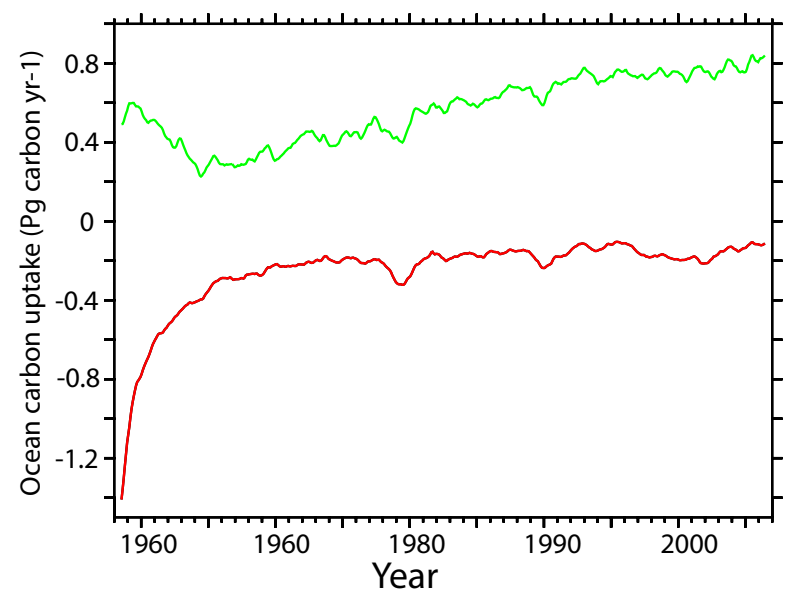

Figure 4. Interannually varying simulated $\mathrm{CO}_{2}$ fluxes over 19582006 as a 12-month running mean, with WSTIR in red and CNTRL in green; (units of $\mathrm{PgC}_{\mathrm{yr}}^{-1}$ ).

CNTRL, carbon uptake increases over the 40-year interval at a rate of $0.125 \mathrm{PgC} \mathrm{yr}^{-1} \mathrm{decade}^{-1}$. The simulated Southern Ocean fluxes between the CNTRL and WSTIR runs thus diverge at a rate of $0.075 \mathrm{Pg} \mathrm{C} \mathrm{yr}^{-1}$ decade $^{-1}$ between 1965 and 2006. The difference in uptake between CNTRL and WSTIR is on the order of $0.9 \mathrm{PgC} \mathrm{yr}^{-1}$ at the end of the simulation (averaged over 2000-2006). The difference between these two runs, which represents uncertainty associated with physical mixing and our ability to model it, is very large when compared to the magnitude of inferred perturbations reported elsewhere for the Southern Ocean uptake of contemporary carbon in response to increasing westerly winds (Le Quéré et al., 2007; Lovenduski et al., 2008; Zickfeld et al., 2007).

Comparing maps of the mean simulated air-sea carbon fluxes between 2000-2006 (Fig. 5a and b) with carbon fluxes calculated from the observed $p \mathrm{CO}_{2}$ climatology of Takahashi et al. (2009) and the gas exchange parameterization of Wanninkhof (1992) (Fig. 5c) shows important differences between the two runs. The difference between WSTIR and CNTRL is explicitly shown in Fig. 5d. Uptake (ingassing) is generally stronger everywhere for CNTRL than for WSTIR. The difference, however, is especially pronounced over not only the Southern Ocean but also the regions in the Northern Hemisphere impacted by storm tracks, reflecting that the mixing length defined in Equation 2 is active over both hemispheres in this study. Over the Southern Ocean, the CNTRL and WSTIR cases bracket the flux climatology calculated from Takahashi et al. (2009), although the weak uptake bias for WSTIR is significantly stronger than the strong uptake bias for CNTRL. It is worth noting that whereas both WSTIR and the data product exhibit a local maximum in outgassing of $\mathrm{CO}_{2}$ along the divergence region around $60^{\circ} \mathrm{S}$, the $\mathrm{CN}-$ TRL case exhibits a local maximum in uptake over this region. 
(a)

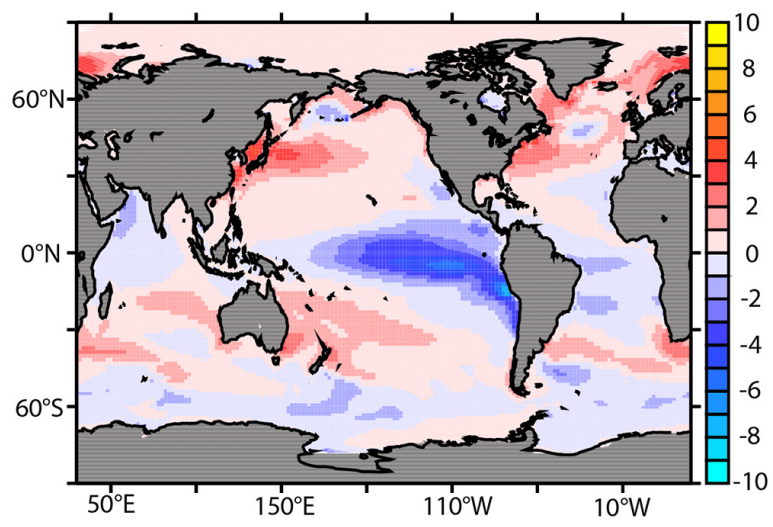

(c)

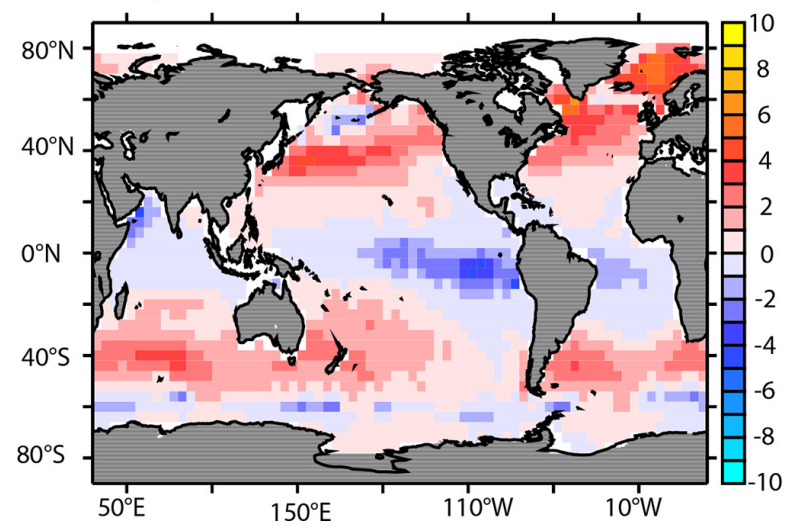

(b)

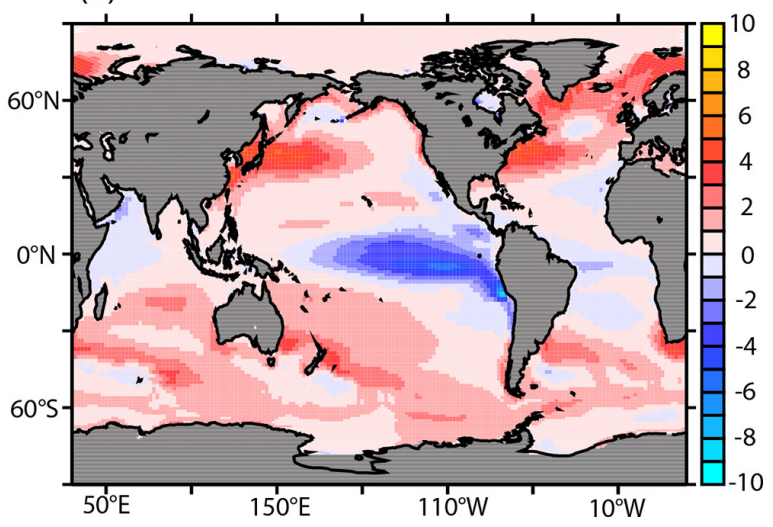

(d)

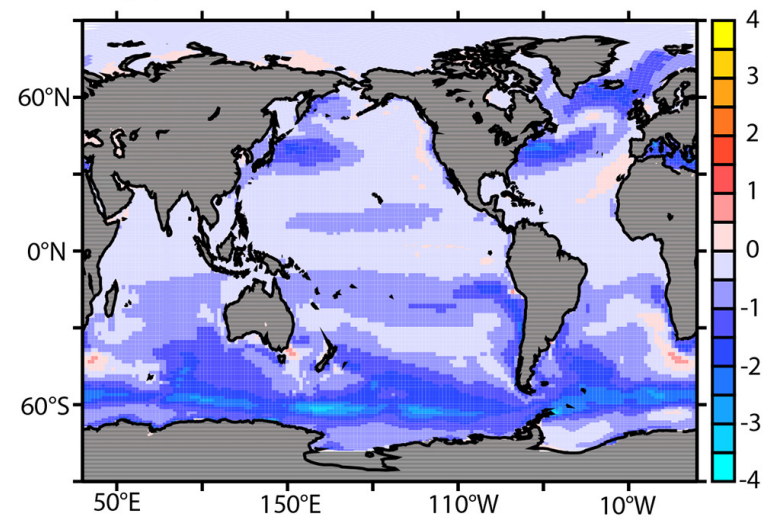

Figure 5. Air-sea $\mathrm{CO}_{2}$ fluxes for WSTIR averaged over 2000-2006 (a), Air-sea $\mathrm{CO}_{2}$ fluxes for CNTRL averaged over 2000-2006(b), Air-sea $\mathrm{CO}_{2}$ fluxes for the climatology of Takahashi et al. (2009) focused on the year 2000 (c), and the air-sea flux differences between the WSTIR and CNTRL simulations (d). In all panels, the units are moles $\mathrm{C} \mathrm{m}^{-2} \mathrm{yr}^{-1}$. Positive values indicate carbon uptake by the ocean.

\subsection{Wind stirring and the seasonal cycles of biogeochemical fields}

Lenton et al. (2013) demonstrated in their Southern Ocean synthesis study that ocean carbon models contain significant biases in their representation of the seasonal cycle of airsea $\mathrm{CO}_{2}$ fluxes over the Southern Ocean. One of their main conclusions was that identifying uncertainties related to specific processes operating over the seasonal cycle should be a priority for future Southern Ocean carbon cycle research. Given that the seasonal timing of re-stratification and destratification, as well as mean summer mixed-layer depths, exercise a fundamental control on upper ocean biogeochemistry, we are motivated to consider here the effect of the windstirring parameterization on the climatological seasonal cycle of various biogeochemical variables. To this end, we characterize the sensitivity of the biogeochemical fields to the perturbations imposed on the physical state as considered in Figs. 2 and 3.

\subsubsection{Carbon and oxygen fluxes}

The climatological seasonal cycle of air-sea $\mathrm{CO}_{2}$ flux, integrated south of $45^{\circ} \mathrm{S}$, is shown in Fig. 6a for CNTRL, WSTIR, and for the data product derived from Takahashi et al. (2009). Observations show that ocean $\mathrm{CO}_{2}$ uptake, relative to the annual mean, occurs in austral summer and outgassing occurs during austral winter. There are significant differences in phase, magnitude, and shape between CNTRL and WSTIR. It is nevertheless clear that this sensitivity is less than the CMIP5 model spread in evidence in Fig. 15b of Anav et al. (2013). Independent sensitivity studies with the PISCES model with the parameter setting in the Geider et al. (1998) representation of growth rates (not shown) indicate a sensitivity that is even larger than that found with mixed-layer depth. Thus, differences in model representation of wind stirring are only expected to contribute part of the difference illustrated by Anav et al. (2013).

As stated previously (Fig. 2d), end-of-winter restratification in CNTRL occurs earlier than in WSTIR. Re-stratification reduces the effect of light limitation earlier in the season in CNTRL, which stimulates biological 
(a)

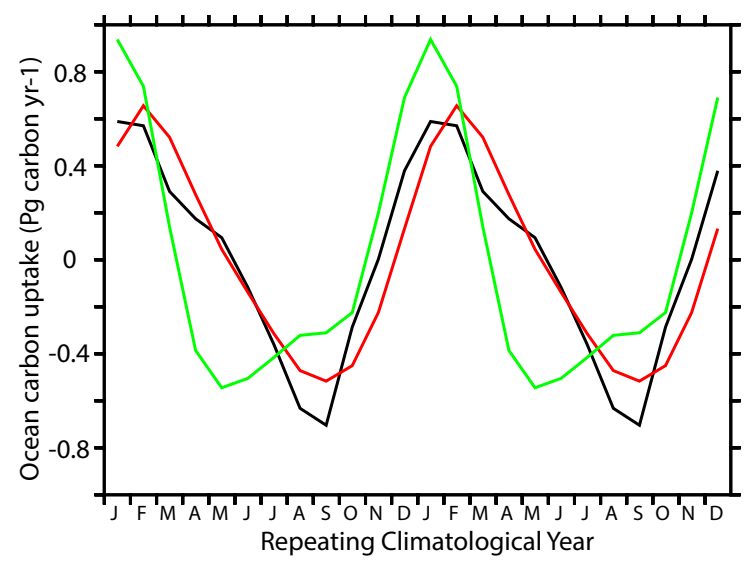

(b)

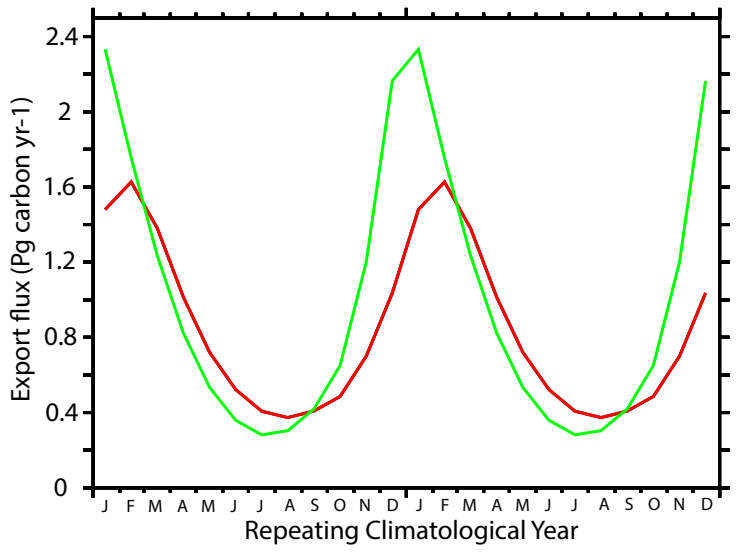

(c)

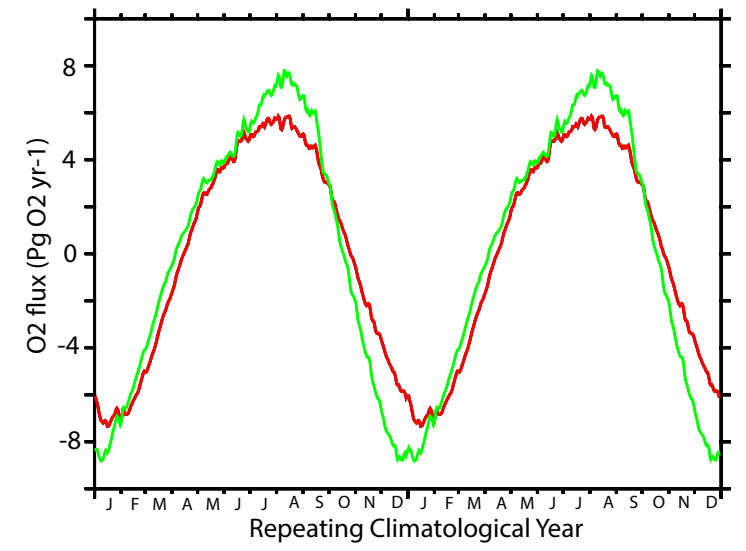

Figure 6. Time variability of Southern Ocean $\left(45-90^{\circ} \mathrm{S}\right)$ fluxes in units of petagrams per year: (a) climatological seasonal cycle of air-sea $\mathrm{CO}_{2}$ fluxes, for the climatology of Takahashi et al. (2009) using the gas exchange parameterization of Wanninkhof (1992) in black, the WSTIR case in red, and the CNTRL case in green; (b) climatological seasonal cycle of carbon export over the Southern Ocean, showing WSTIR (red) and CNTRL (green); (c) climatological seasonal cycle of air-sea $\mathrm{O}_{2}$ fluxes, for WSTIR (red) and CNTRL (green).

production and enhances the biological drawdown of dissolved inorganic carbon (DIC) in the ocean's surface layer earlier in the season for CNTRL than for WSTIR. Inclusion of the ad hoc wind stirring parameterization delays the onset of the winter reversal from outgassing to ingassing by 3 to 4 months (Fig. 6a) relative to CNTRL. The winter outgassing peak in CNTRL, however, is much too early relative to observations.

Aside from changing the phasing and amplitude of the seasonal cycle, the ad hoc parameterization also impacts the skewness of the climatological seasonal cycle of air-sea $\mathrm{CO}_{2}$ fluxes. The exaggerated skewness found for CNTRL relative to the observational product and WSTIR at least in part reflects the sharp skewness in biological processes revealed in the diagnostic of seasonality in export (Fig. 6b). The sharp peak in export production in January for CNTRL relative to WSTIR is a consequence of light limitation being less for
CNTRL relative to WSTIR. Integrated over the seasonal cycle, the Southern Ocean export is $1.48 \mathrm{Pg} \mathrm{C} \mathrm{yr}^{-1}$ for WSTIR and $2.33 \mathrm{Pg} \mathrm{C} \mathrm{yr}^{-1}$ for CNTRL. Southern Ocean carbon export in CNTRL is thus $58 \%$ larger than in WSTIR even if, globally, both have nearly identical annual mean export values of $7.4 \mathrm{Pg} \mathrm{C} \mathrm{yr}^{-1}$.

The climatological seasonal cycle of air-sea $\mathrm{O}_{2}$ fluxes is shown in Fig. 6c for CNTRL and WSTIR. To be consistent with the $\mathrm{CO}_{2}$ flux in Fig. 6a and b, positive $\mathrm{O}_{2}$-flux values in Fig. $6 \mathrm{c}$ represent a flux into the ocean. In agreement with the carbon flux, there exist differences in phasing between the summer peak releases of $\mathrm{O}_{2}$ to the atmosphere, with the peak occurring approximately four weeks earlier for CNTRL than for WSTIR. For the case of the winter extremum, on the other hand, CNTRL slightly lags WSTIR. This contrasts with the phasing of $\mathrm{CO}_{2}$. Additionally, the amplitude of the seasonal 
$\mathrm{O}_{2}$ flux cycle is approximately $25 \%$ larger for CNTRL than for WSTIR.

Clearly the sensitivity of $\mathrm{O}_{2}$ fluxes to the ad hoc wind stirring parameterization does not perfectly mirror the sensitivity seen for $\mathrm{CO}_{2}$ fluxes in Fig. 6a. Differences in the impact on the seasonality of $\mathrm{O}_{2}$ and $\mathrm{CO}_{2}$ fluxes should be expected, given that air-sea equilibration timescales for $\mathrm{O}_{2}$ are approximately an order of magnitude more rapid than for $\mathrm{CO}_{2}$. However, differences in entrainment of $\mathrm{O}_{2}$ and $\mathrm{CO}_{2}$ across the base of the mixed layer are also expected to be important.

Given the relatively short duration of the WSTIR perturbation relative to CNTRL (decades), it should be emphasized that this sensitivity of air-sea fluxes of contemporary carbon does not provide insight into the future 21 st century uptake capacity of the Southern Ocean to anthropogenic carbon. The analysis also reveals that the differences are manifested in $\mathrm{O}_{2}$ fluxes, with the perturbations to $\mathrm{O}_{2}$ not being perfectly redundant to the changes in $\mathrm{CO}_{2}$ fluxes.

\subsubsection{Chlorophyll and blooms}

Remotely sensed surface chlorophyll from the Sea-viewing Wide Field-of-view Sensor (SeaWiFS, http://oceancolor. gsfc.nasa.gov/) is used here as a metric to evaluate the modeled seasonal cycle and ecological effects of the wind stirring parameterization. A seasonal climatology was constructed over the period 1998-2006 to address both the timing of maximum seasonal chlorophyll concentrations and the timing of bloom onset. To create the climatology, SeaWiFS data were first put on the same grid as the ocean model. Modeled chlorophyll and regridded SeaWiFS data were then averaged to 8-day mean fields. In order to focus on local comparisons and minimize extrapolation errors due to missing data where storms and other phenomena have obscured data retrieval, the model was sampled only at space-time coordinates where SeaWiFS observations are available.

The timing of the climatological maximum chlorophyll concentrations is considered in Fig. 7 for SeaWiFS (Fig. 7a), CNTRL (Fig. 7b), and WSTIR (Fig. 7c). The timing of maximum chlorophyll concentrations has better agreement with observations for WSTIR than for CNTRL. Within the latitude band $50-60^{\circ} \mathrm{S}$, the SeaWiFS product indicates peak concentrations largely within November and December, with early November maxima tending to fall along $60^{\circ} \mathrm{S}$. For CNTRL, there are large expanses where September maxima are in evidence over $50-60^{\circ} \mathrm{S}$, thereby leading the observations in phase by as much as 2 months. For the WSTIR case, the phase lead is on the order of 1 month relative to the observations.

We then consider the timing of bloom onset shown in Fig. 8. The onset timing was chosen for each surface grid point as the time when chlorophyll concentrations increased above the median level plus $0.2 \mathrm{mg} \mathrm{m}^{-3}$ during the 4-month period preceding the seasonal chlorophyll maximum (a for-
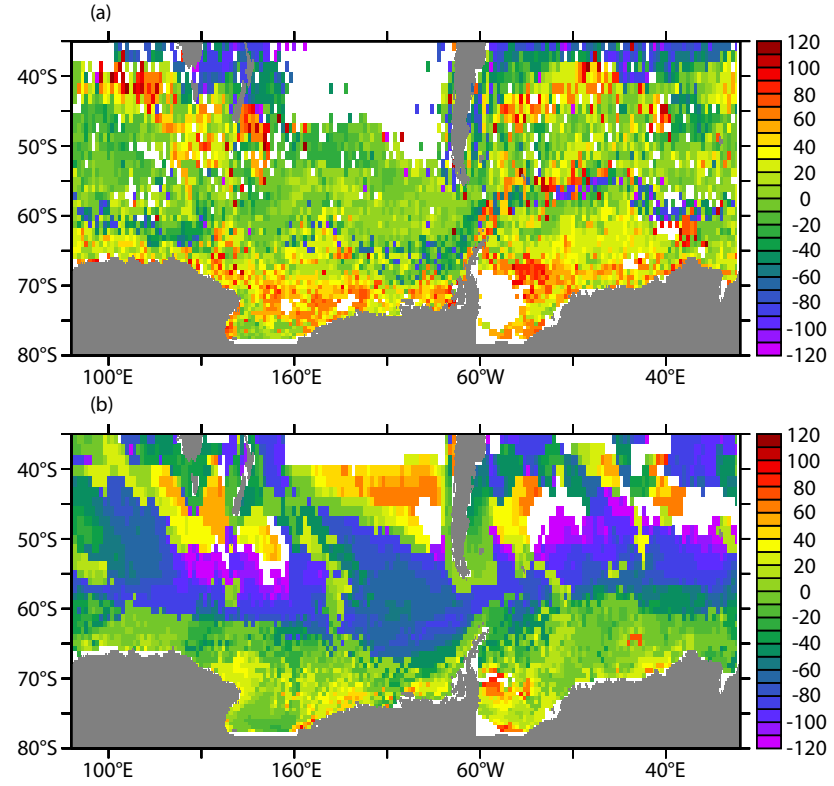

(c)

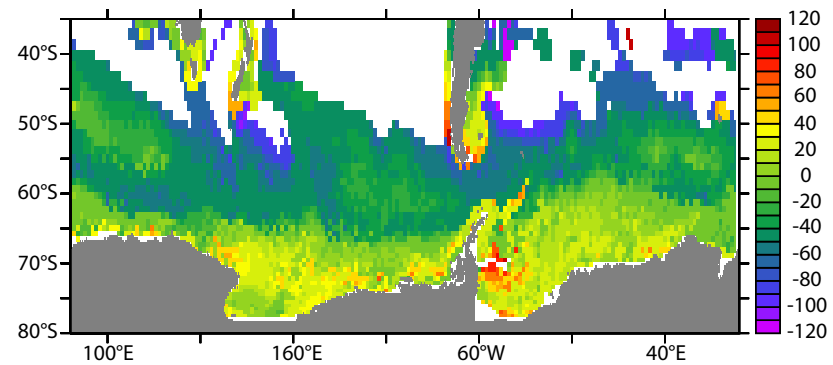

Figure 7. Seasonal phasing of the peak chlorophyll concentrations for (a) SEAWIFS, (b) CNTRL, and (c) WSTIR; units are days for a climatological year. Regions where the quantity is not well or defined or where the quantity and/or bloom are not well-defined are shown in white.

mulation considering the median plus $5 \%$ was also tried, but this multiplicative formulation had trouble in cases with a double-peak seasonal cycle of chlorophyll). Bloom onset is shown for SeaWiFS (Fig. 8a), CNTRL (Fig. 8b), and WSTIR (Fig. 8c).

Modeled bloom onset for both CNTRL and WSTIR leads the observations by $4-6$ weeks over $50-60^{\circ} \mathrm{S}$, with the differences between the model runs being smaller for bloom onset than for the timing of maximum chlorophyll concentrations. However, the peak chlorophyll concentrations occur approximately one month later for WSTIR than they do for CNTRL, consistent with what was noted previously for not only mixed layer depth seasonal phasing (in particular for stratification over $50-60^{\circ} \mathrm{S}$ ), but also in $\mathrm{CO}_{2}$ and $\mathrm{O}_{2}$ fluxes. 

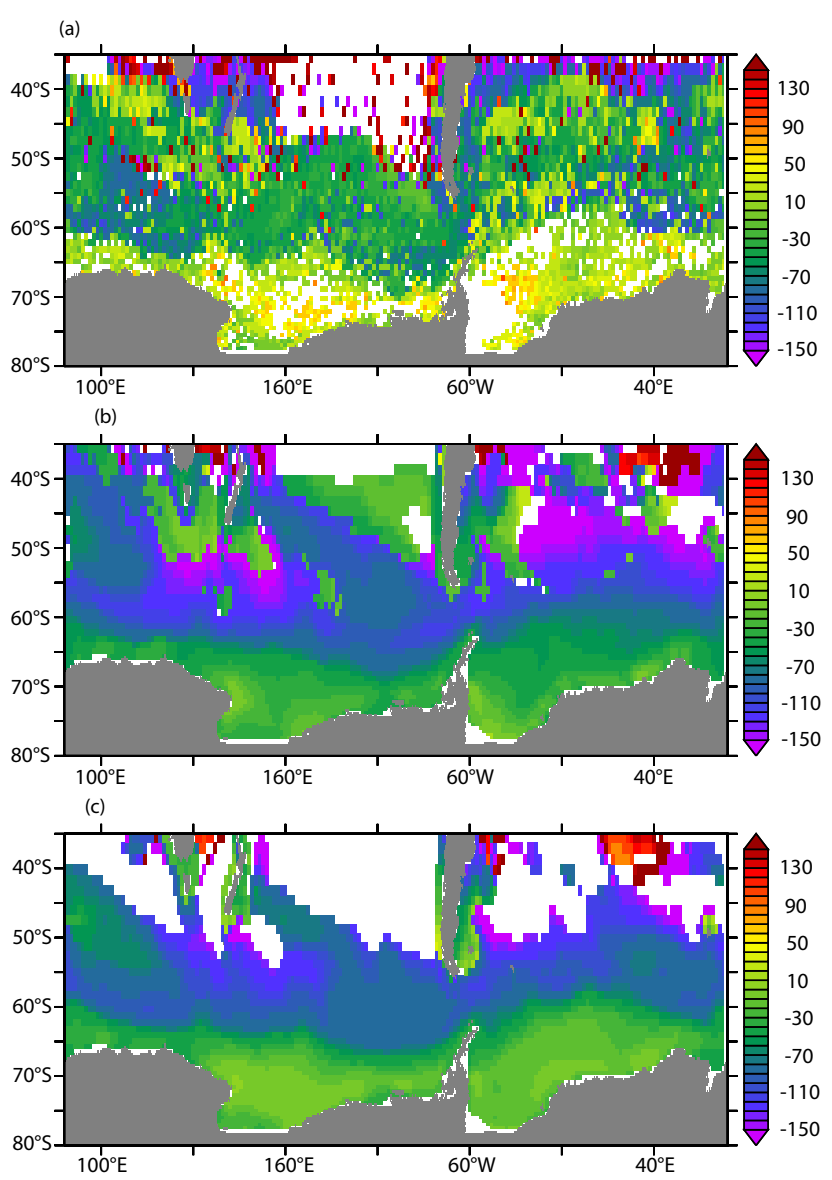

Figure 8. Phasing of the bloom onset timing for (a) SEAWIFS, (b) CNTRL, and (c) WSTIR; units are days for a climatological year. Regions where the quantity is not well or defined or where the quantity and/or bloom are not well-defined are shown in white.

\subsection{Influence of increased wind stirring on atmospheric potential oxygen}

Next we consider the simulations of atmospheric potential oxygen (APO) for the two models. The observed and simulated climatological seasonal cycles of APO at Cape Grim (CGO) station in Tasmania $\left(40.68^{\circ} \mathrm{S}, 144.69^{\circ} \mathrm{E}\right)$ and Palmer Station (PSA) station on the Antarctic Peninsula $\left(64.46^{\circ} \mathrm{S}\right.$, $64.03^{\circ} \mathrm{W}$ ), two stations from the Scripps network, are shown in Fig. 9. Cape Grim (Fig. 9e) is located north of the Antarctic Circumpolar Current (ACC) and is thereby a footprint region that is subtropically influenced, in contrast to PSA (Fig. 9f), which is located south of the ACC.

For the models the climatological seasonal cycle is calculated using daily output, and for the observations weekly flask measurements (snapshots) are used. As a first step, the model output and the data are interpolated onto a regular weekly time grid using a seasonal-trend decomposition by loess (STL) algorithm (Cleveland et al., 1990), which calculates a gradually evolving seasonal cycle and trend for time series data without including any assumptions about the functional form of these quantities. The data is then detrended by subtracting the seasonal cycle that is calculated using STL, and a climatological mean seasonal cycle is calculated. Hovmöller diagrams showing the seasonal cycle of APO as a function of latitude for WSTIR and CNTRL are shown in Fig. 9a and b. In both cases, the APO has been detrended to emphasize the phasing and amplitude of the climatological seasonal cycle of each latitude band.

The seasonal maximum APO occurs later for WSTIR (Fig. 9a) than for CNTRL (Fig. 9b), and the amplitude of the seasonal cycle over the latitude range $60-65^{\circ} \mathrm{S}$ is larger for CNTRL than for WSTIR. Additionally, the WSTIR maximum (January to March) peak is broader than the CNTRL peak. These differences in phase and amplitude are dominated by $\mathrm{O}_{2}$ (relative to $\mathrm{CO}_{2}$ and $\mathrm{N}_{2}$, not shown) and are consistent with the phase shift in $\mathrm{O}_{2}$ fluxes over the Southern Ocean between the CNTRL and WSTIR cases (Fig. 6c). In order to test the importance of the $\mathrm{O}_{2}$ contribution to the total APO signal, the variations driven by the $\mathrm{O}_{2}$ fluxes alone, with the $\mathrm{N}_{2}$ and $\mathrm{CO}_{2}$ components held at a constant value, are considered explicitly for WSTIR (Fig. 9c) and CNTRL (Fig. 9d). These two panels reveal the dominance of surface $\mathrm{O}_{2}$ fluxes in driving the total APO signal over the extratropics of the Southern Hemisphere when compared to the fields shown in Fig. 9a and b. The $\mathrm{O}_{2}$ contribution alone is considered explicitly for WSTIR (Fig. 9c) and CNTRL (Fig. 9d), revealing the dominance of this contribution to the total APO signal.

The observed climatological seasonal cycles of APO from site CGO and PSA are shown in Fig. 9e and 9f, where they are also compared with the seasonal cycle from CNTRL and WSTIR. At CGO, the simulated APO seasonal cycle is in good agreement between CNTRL and WSTIR (Fig. 9e), although the seasonal amplitude for both CNTRL and WSTIR is slightly smaller than observed. The wind stirring perturbation has only a minor effect on the seasonal cycle of APO north the ACC, in agreement with Fig. $9 \mathrm{~b}$.

At PSA (Fig. 9f), which is south of the ACC, the seasonal cycle of CNTRL has a distinctively greater magnitude and is slightly phase shifted, leading slightly the seasonal cycle of WSTIR. The phasing of the seasonal cycle for WSTIR is in better agreement with the observations at PSA than for CNTRL. However, from this analysis alone it is not yet clear how the relative contributions of atmospheric $\mathrm{O}_{2}$ and $\mathrm{CO}_{2}$ variations contribute to the phasing of APO at PSA for WSTIR and CNTRL (Fig. 9f). The sensitivity of APO to the wind stirring parameterization is stronger south of the ACC because the near surface oceanic vertical $\mathrm{O}_{2}$ concentration gradient is larger to the south of the ACC than to the north of it.

The potential importance of this sensitivity to wind stirring that was considered for a climatology in Fig. 9 can also be considered for the case of year-to-year variations. In Fig. 10a we consider for Palmer Station the seasonal evolution of 
(a)

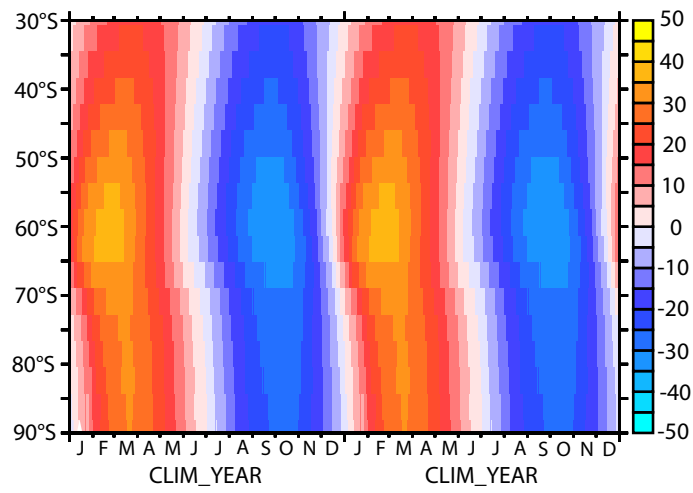

(c)

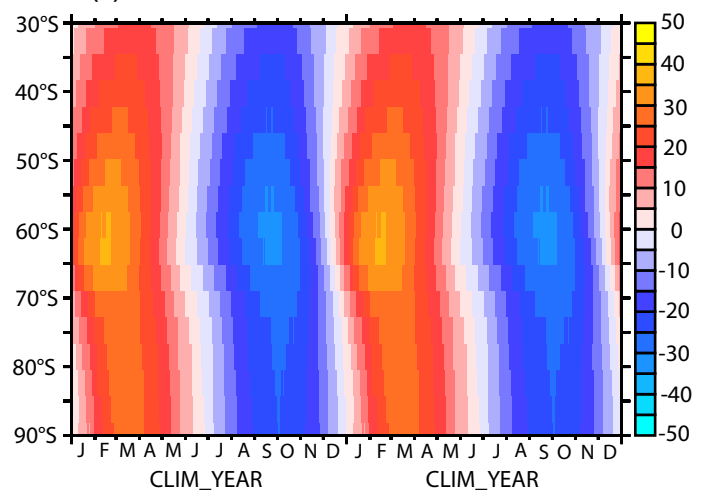

(e)

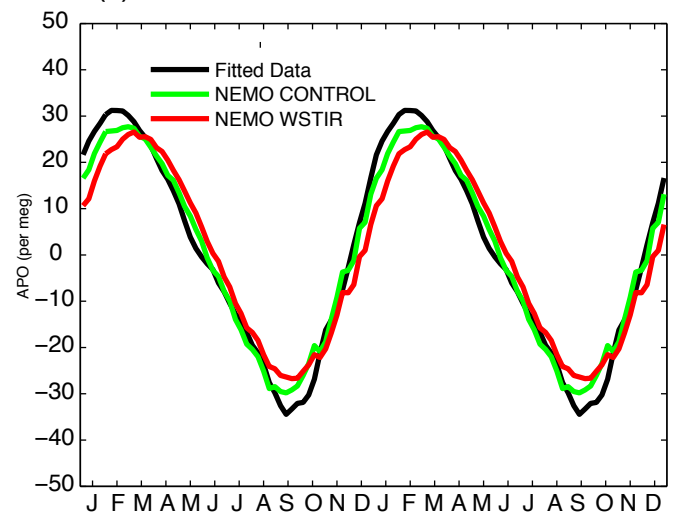

(b)

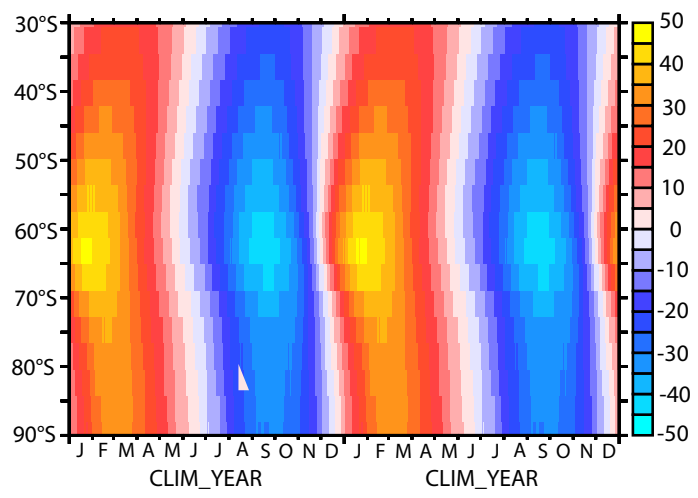

(d)

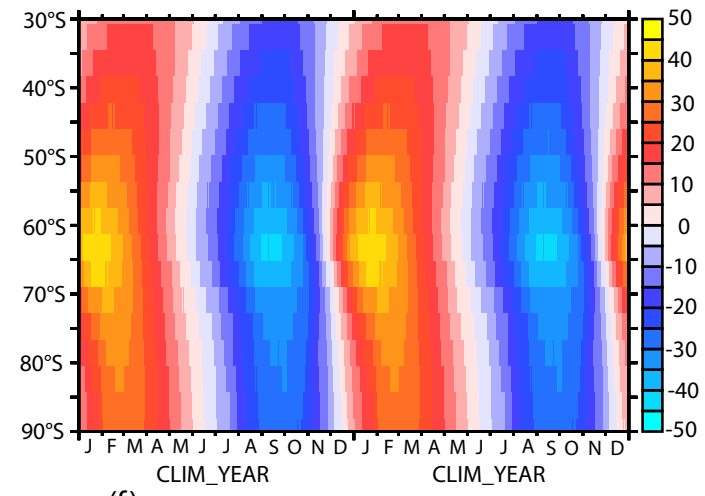

(f)

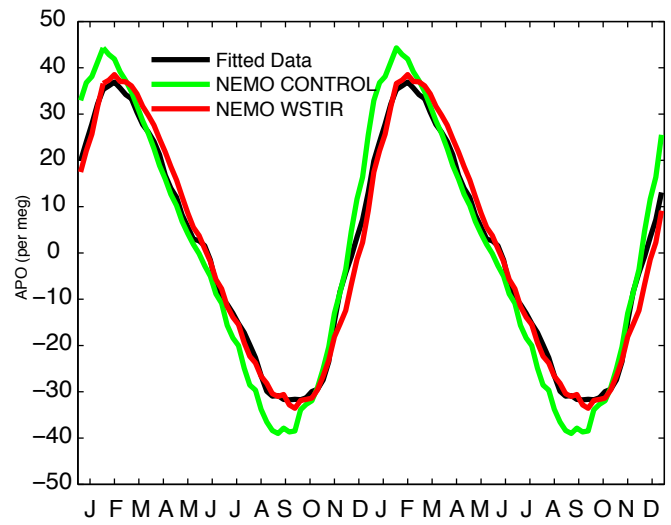

Figure 9. Atmospheric potential oxygen (APO) as simulated by the atmospheric transport model (ATM), in per meg units, for a detrendended climatological cycle. In each panel, the seasonal cycle is represented twice. Hovmöller diagram of canonical seasonal cycle of zonal mean surface APO for CNTRL case (a); Hovmöller diagram of canonical seasonal cycle of zonal mean surface APO for WSTIR case (b); Hovmöller diagram showing the relative contribution of $\mathrm{O}_{2}$ to climatological APO variations for WSTIR (c); Hovmöller diagram showing the relative contribution of $\mathrm{O}_{2}$ to climatological APO variations for CNTRL (d); Cape Grim, Australia (CGO): Repeated climatological seasonal cycle compared with observations from Scripps network; here the climatological seasonal cycle is calculated using the STL analysis tools of Cleveland et al. (1990) (e). Palmer Station, Antarctica (PSA): Repeated climatological seasonal cycle compared with observations from Scripps network; Here the climatological seasonal cycle is calculated using the STL analysis tools of Cleveland et al. (1990) (f).

APO over years 1998 to 2011. For each realization of the seasonal cycle, we consider the time interval 1 July to 30 June as a separate line over years 1998 to 2011. For each case, the seasonal cycle is repeated twice with the same line to facilitate interpretation. For the decade that corresponds to the period of overlap between the observations and the model (1995-2005), solid lines are used in Fig. 10, with dashed lines being used to represent the more recent period. Each colored line shows a different year. Clearly there are year-toyear differences in both the amplitude of the seasonal cycle 
(a)

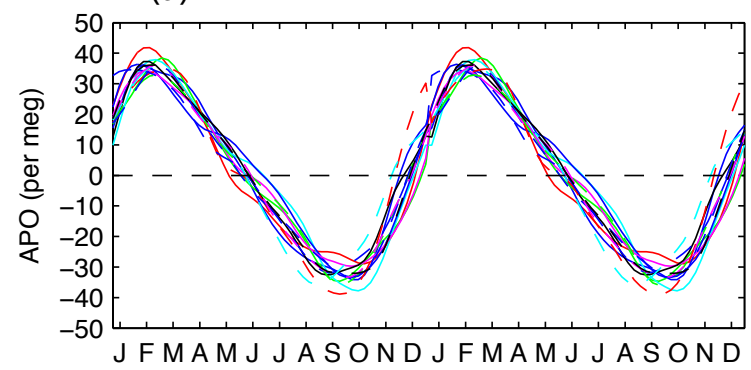

(b)

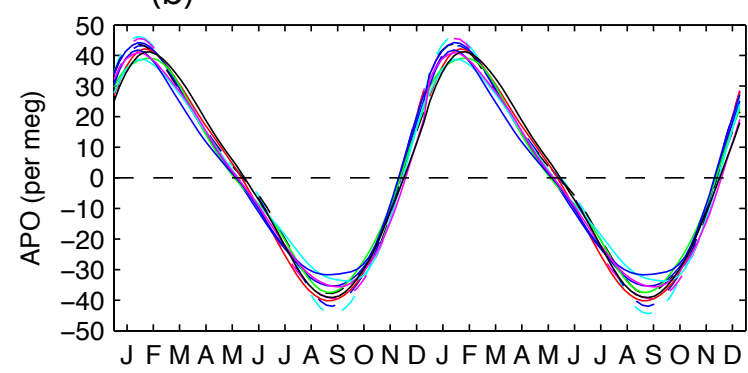

(c)

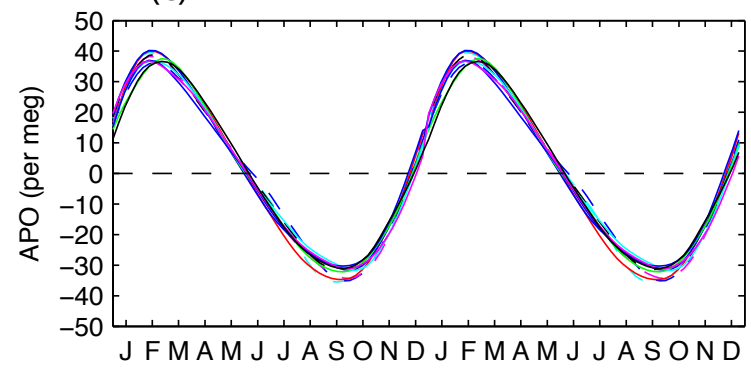

(d)

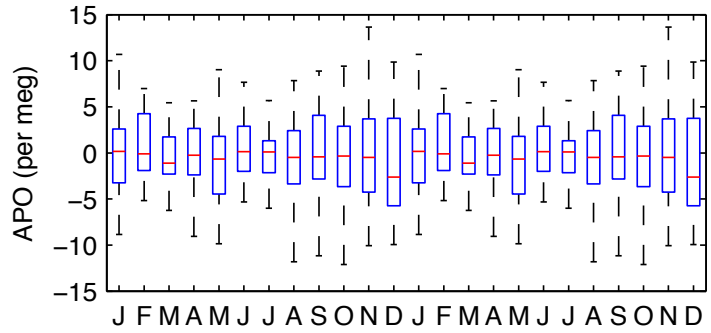

(e)

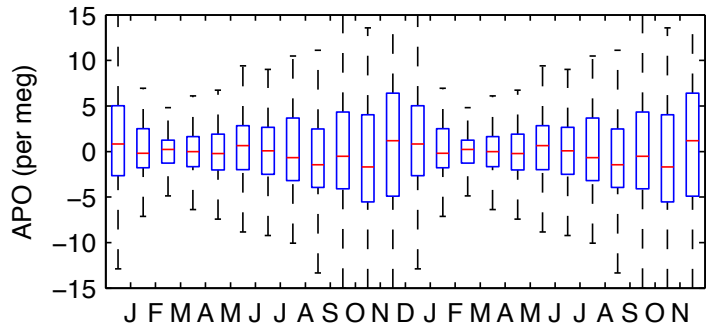

(f)

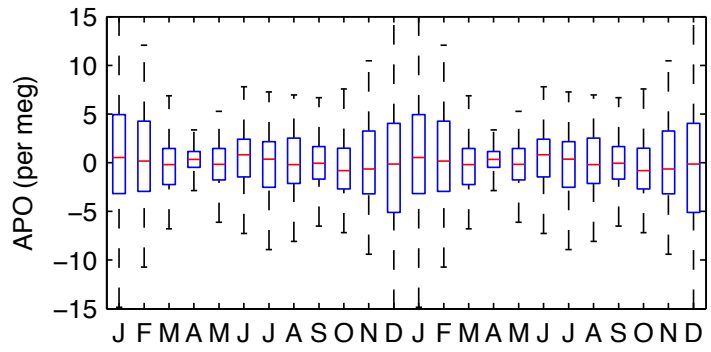

Figure 10. Atmospheric potential oxygen (APO), with each year shown separately over 1 July-30 June. (a) Observations from Scripps network, with each line corresponding to a separate year but repeated twice to facilitate interpretation. Each line represents a different year between 1998 and 2011. Solid lines are used for years that overlap with the model runs (1998-2005), while dashed lines are used for the more recent observations. (b) Model output from the CNTRL case over the period 1994-2005, with each line corresponding to a separate year but repeated twice. Solid lines are used for years that overlap with the observations (1998-2005), while dashed lines are used for the earlier period. (c) Model output from the WSTIR case, with each line corresponding to a separate year but repeated twice. Time period follows (b). (d) Observations, bar and whiskers plot of intraseasonal variability inferred from STL analysis, with red lines showing mean (per meg) deviations, and blue boxes marking 25th and 75th percentile values of intraseasonal variations. Bars represent the full range of values, but outliers defined as values larger than 1.5 times the interquartile range, have been excluded. Time period follows (a). (e) Same as (d), but for CNTRL. Time period follows (b). (f) Same as (e), but for WSTIR. Time period follows (b).

and the phase of the seasonal periods of increasing and decreasing APO. We infer from what we have seen in Fig. $9 f$ for Palmer Station climatologies that APO is sensitive to the phasing of the re-stratification and de-stratification over the Southern Ocean. Might this inference from a comparison of the respective WSTIR and CNTRL climatologies be supported by either of the runs considered individually?

Clearly for the individual cases of WSTIR (Fig. 10b) and CNTRL (Fig. 10c) considered separately, the year-to-year variations in the phase and amplitude of the seasonal cycle are significantly smaller than what is seen in the observations (Fig. 10a). This is an important illustration of both the power of APO as a tracer and the shortcomings of the ad hoc parameterization. The ad hoc parameterization can be used to tune the climatological seasonal cycle, but it is not expected to represent year-to-year changes in the phasing of the seasonal cycle. We have shown this in order to emphasize two main points: (a) the WSTIR versus CNTRL sensitivity is important for demonstrating the sensitivity of biogeochemistry to wind stirring and (b) that though tuned for representing the climatological cycle, the ad hoc wind stirring parameterization is not process-based and should not necessarily be relied upon for an improved simulation of intraseasonal variations. 
Next we consider intraseasonal variations in APO as inferred for Palmer Station for both the observations and the two model runs in bar and whiskers diagrams. A secondorder low-pass Butterworth filter was applied to weekly mean observations and model output fields with a cutoff frequency of $1 / 6$, retaining information with frequencies lower than 6 weeks. The panel for Palmer Station (Fig. 10d) reveals the median (red line), the 25 th-27th percentile variations (black box). Outliers, which are defined as being more than 1.5 times the inter-quartile variations, are not shown. The whiskers show the highest and lowest excursions that are not considered outliers for each month. Importantly, the intraseasonal variations reveal amplitude modulations over the seasonal cycle, with variations in austral spring (on the order of 15 per meg) twice as large as variations in austral autumn. From this analysis alone, it is not clear whether intraseasonal processes in the ocean or the atmosphere (or both) drive the intraseasonal variations in APO with inherent timescales on the order of weeks.

The intraseasonal variations for the CNTRL run (Fig. 10e) and the WSTIR run (Fig. 10f) are qualitatively similar to the observations in terms of modulations of the amplitude over the seasonal cycle. Nevertheless there are important differences between CNTRL and WSTIR. The timing of maximum amplitude intraseasonal variations in CNTRL during austral spring peaks earlier than in WSTIR, even though the atmospheric transports used for these two APO simulations are identical. This implicates the surface air-sea fluxes driving APO variations as being important. It is still not clear if this occurs through their slowly varying impact on the mean meridional gradients in APO during spring or through intraseasonal variations in the surface fluxes themselves, since the atmospheric simulations were forced with daily varying air-sea fluxes. As can be seen in Fig. 9a and b, large-scale meridional gradients in APO at the latitude of Palmer Station are not pronounced in either WSTIR or CNTRL in austral spring, and are thereby the variations in evidence in Fig. 10d are consistent with elevated intraseasonal variability in airsea fluxes in austral spring.

Within the larger context of climatologies emphasized in this paper, we wish to emphasize that the APO measured at Palmer Station exhibits information over a broad range of timescales. It is not yet clear whether the year-to-year changes in the phasing of the seasonal cycle (Fig. 10a) are independent of the modulations of intraseasonal variability (Fig. 10b). Nevertheless the intraseasonal variations in APO are not randomly distributed over the seasonal cycle.

\subsection{Influence of wind stirring on surface and interior nutrient distributions}

We also consider the impact of wind stirring on surface nutrients $\mathrm{Fe}$ and $\mathrm{NO}_{3}$. The concentration of $\mathrm{Fe}$ averaged over 2000-2006 is shown for WSTIR (Fig. 11a), CNTRL (Fig. 11b), and the difference between these two runs (Fig. 11c). Likewise, the analogous distributions for $\mathrm{NO}_{3}$ are shown for WSTIR (Fig. 11d), CNTRL (Fig. 11e), and the difference (Fig. 11f).

This reveals that the annual mean $\mathrm{Fe}$ concentrations are lower for WSTIR than for CNTRL, while the annual mean $\mathrm{NO}_{3}$ concentrations are higher. Enhanced summer entrainment for WSTIR relative to CNTRL should sustain both higher $\mathrm{Fe}$ and $\mathrm{NO}_{3}$ concentrations, but under light-limited conditions, $\mathrm{Fe}$ and $\mathrm{NO}_{3}$ have different response functions, resulting in a situation where $\mathrm{NO}_{3}$ increases but Fe decreases when vertical mixing increases. For $\mathrm{NO}_{3}$, enhanced light limitation associated with enhanced mixed-layer depths results in high surface $\mathrm{NO}_{3}$ concentrations relative to CNTRL, adding to the entrainment signal. For Fe, on the other hand, the Fe / DIC ratio of biological uptake increases as a consequence of light limitation, and biology consumes increasingly more $\mathrm{Fe}$, thereby driving a tendency towards decreased Fe concentrations. This behavior is common to biogeochemical models over the Southern Ocean by design, but Strzepek et al. (2012) have recently argued that this is not consistent with observations. This strong sensitivity demonstrated here, and the controversy surrounding it, should serve to motivate further work to understand how the Fe / DIC ratio changes under light limitation.

What are the consequences for $\mathrm{NO}_{3}$ and DIC distributions in the ocean interior? In Fig. 12, we consider the distribution of $\mathrm{NO}_{3}$ and DIC concentrations projected onto $\sigma_{0}=26.8$ (Subantarctic Mode Water (SAMW) density class), with averaged concentrations calculated over the period 2000-2006. The two runs were "split" in 1958, and thus this represents a perturbation signal of approximately 45 years. The distribution of $\mathrm{NO}_{3}$ is shown for WSTIR (Fig. 12a), for CNTRL (Fig. 12b), and for the difference between these two runs (Fig. 12c). The interior concentration of $\mathrm{NO}_{3}$ is higher for WSTIR than for CNTRL, consistent with Fig. 11f considering the outcrop latitude of the $\sigma_{0}=26.8$ isopycnal. Given that the difference in $\mathrm{NO}_{3}$ concentrations reflects the signal $\sim 45$ years into the perturbation, it is not surprising that the perturbation is largest over the Southern Hemisphere subtropical gyres given the multi-decadal timescales for this region (see Fig. 3 of Rodgers et al. (2003) for relevant Lagrangian diagnostics), with a smaller-amplitude signal having accessed via ocean interior transport the equatorial upwelling region of the Pacific.

Differences in nutrients transported out of the Southern Ocean between CNTRL and WSTIR have important implications for the supply of nutrients to the low latitudes. Sarmiento et al. (2004) argued that $75 \%$ of the low latitude 
(a)

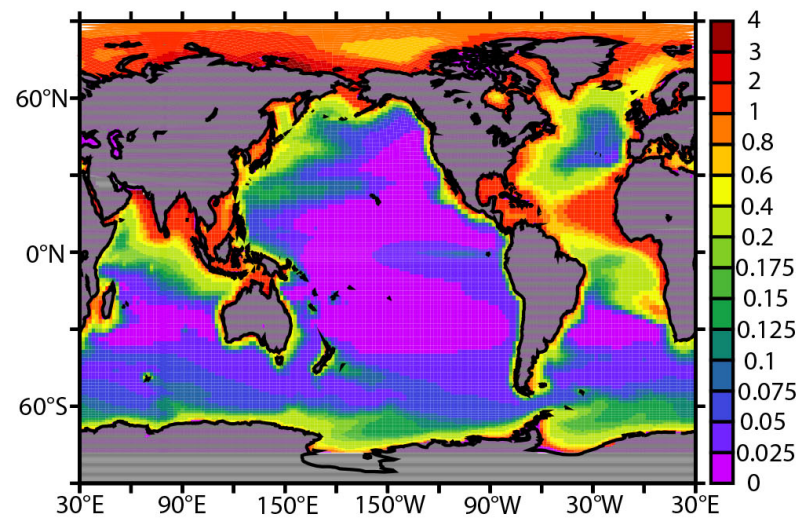

(b)

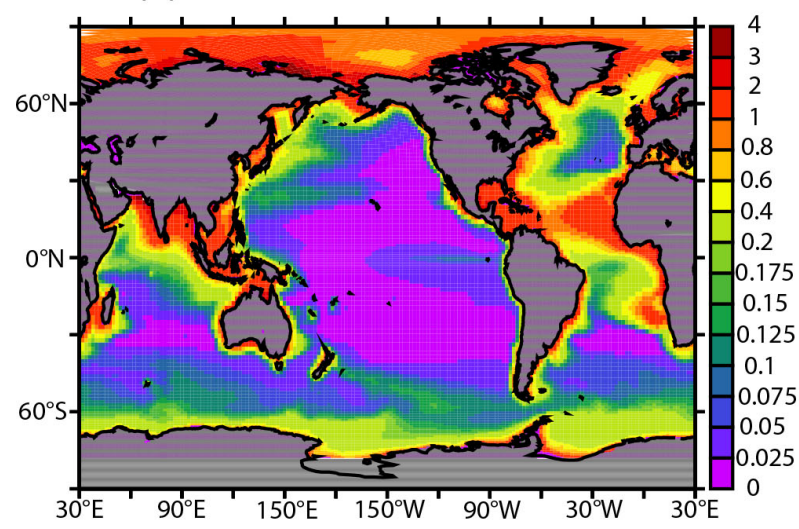

(c)

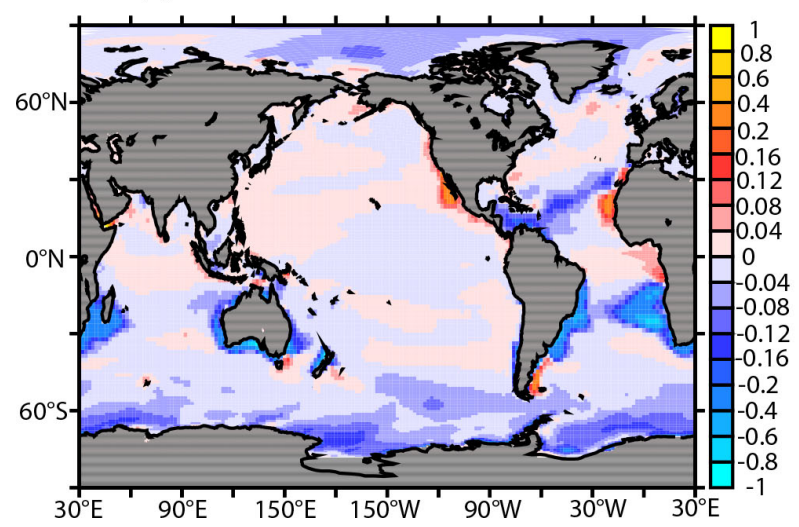

(d)

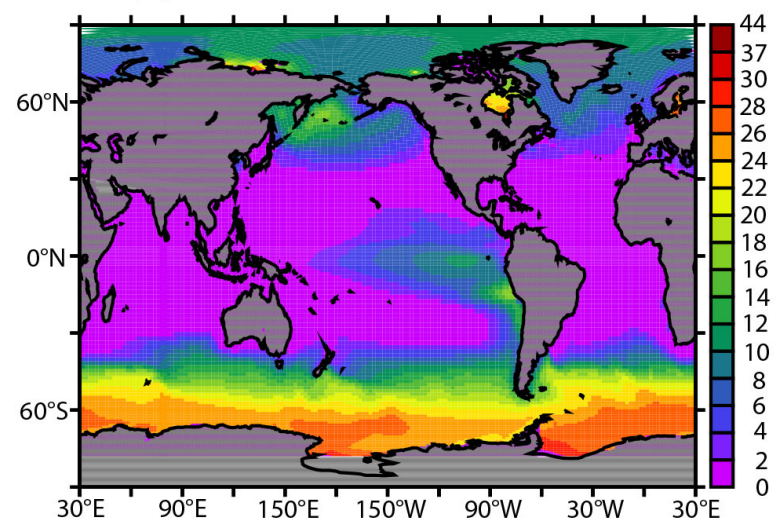

(e)

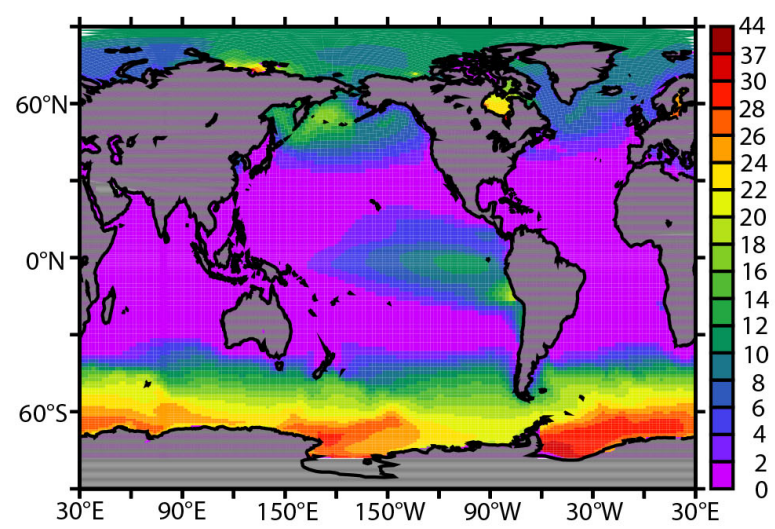

(f)

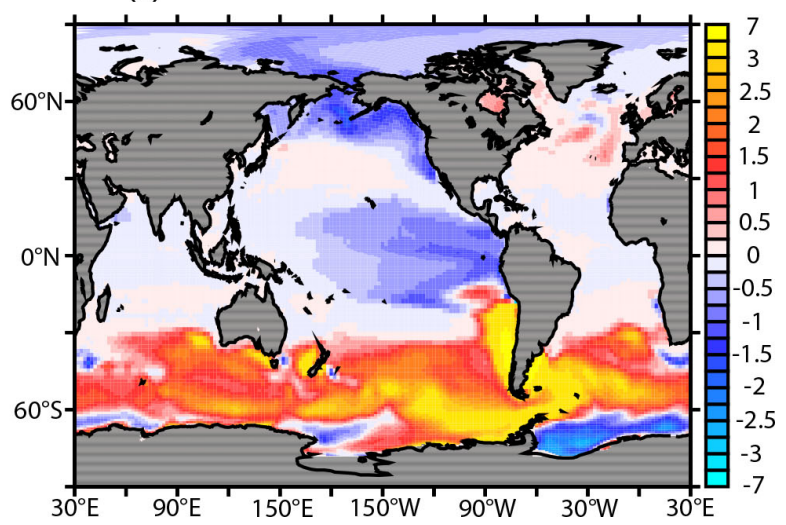

Figure 11. Surface concentrations are shown averaged over years 2000-2006 for (a) Fe in WSTIR, (b) Fe in CNTRL, and (c) the difference in Fe between WSTIR and CNTRL (units of nM). Surface concentrations are shown averaged over years 2000-2006 for (d) NO 3 in WSTIR, (e) $\mathrm{NO}_{3}$ in CNTRL, and (f) the difference in $\mathrm{NO}_{3}$ between WSTIR and CNTRL (units of $\mu \mathrm{M}$ ).

biological productivity is fueled by nutrients exported from the Southern Ocean in the SAMW density class. Viewed as an estimate of uncertainty, the results presented here for $\mathrm{NO}_{3}$ concentrations underscore the potential importance of wind stirring over the Southern Ocean for larger-scale nutrient supply over the global ocean.
In Fig 12d and e we consider the simulated DIC concentrations for both model WSTIR and CNTRL for the same $\sigma_{0}=26.8$ density surface, as well as an average over 20002006, and also the difference in DIC concentrations between the simulations in Fig. 12f. In the large-scale distribution of the DIC distribution for the WSTIR and CNTRL cases, there are a number of important similarities with the patterns found 
(a)

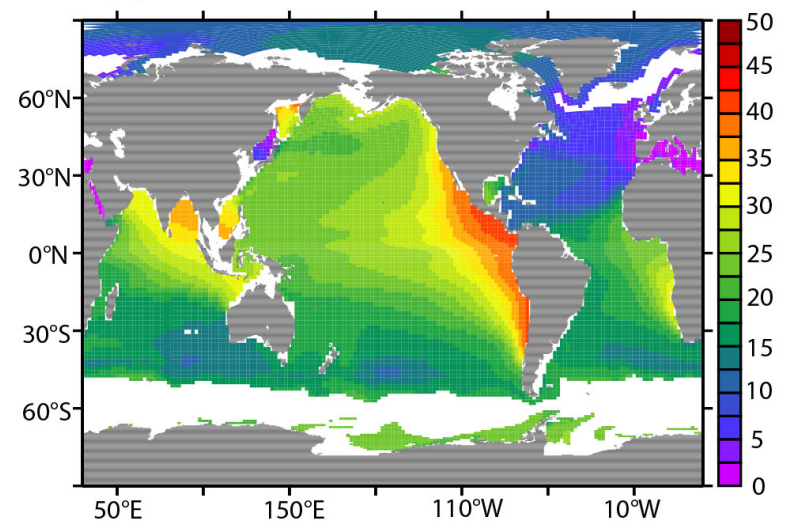

(b)

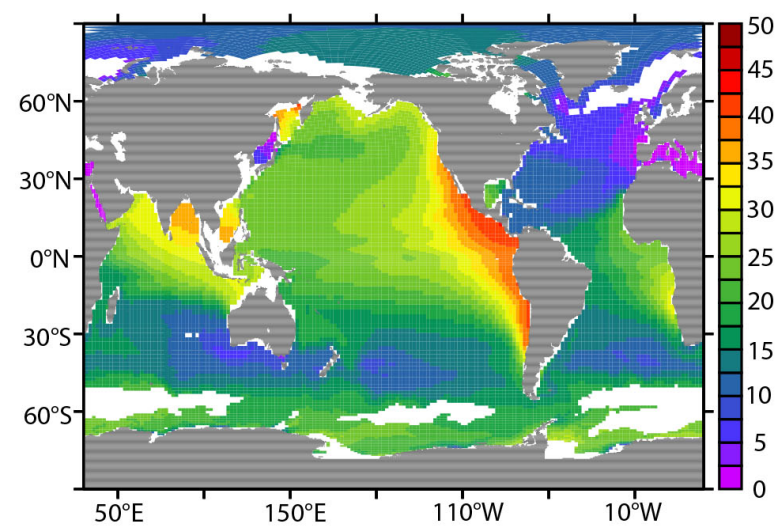

(c)

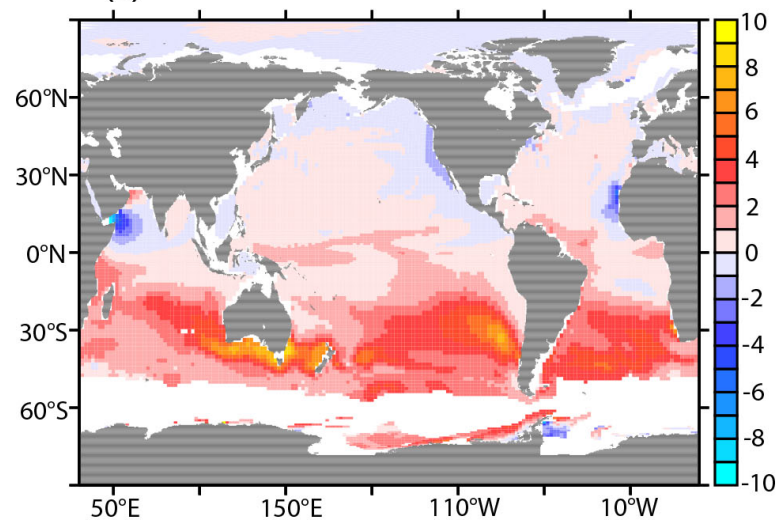

(d)

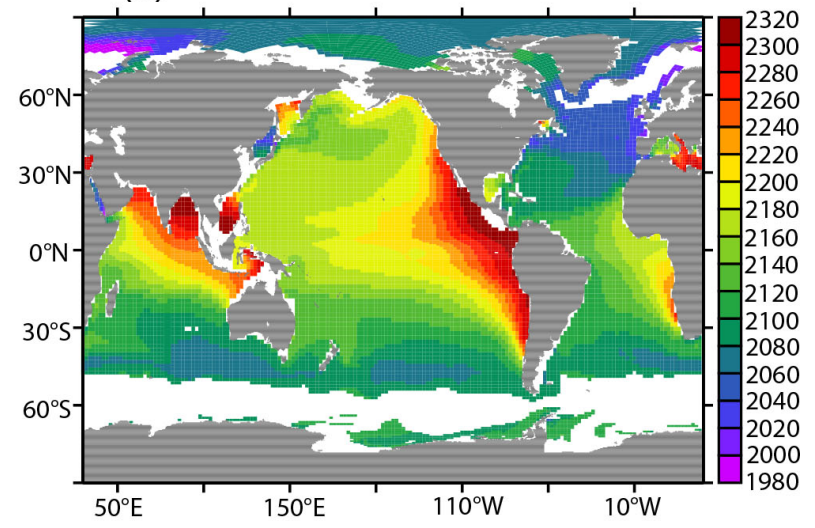

(e)

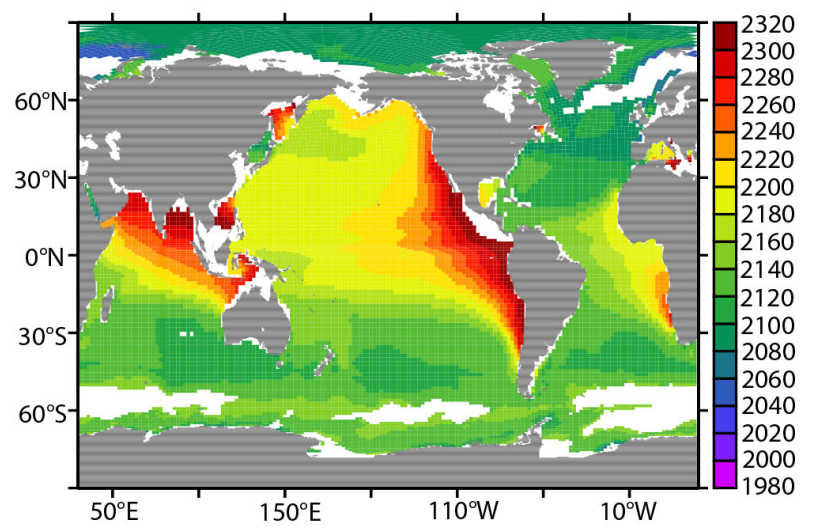

(f)

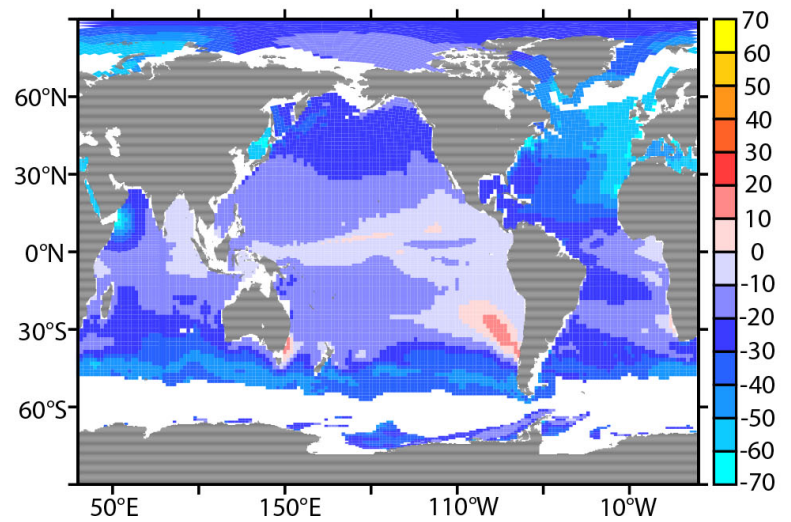

Figure 12. Ocean interior concentrations $\left(\sigma_{0}=26.8\right)$ are shown averaged over years 2000-2006 for (a) $\mathrm{NO}_{3}$ in WSTIR, (b) $\mathrm{NO}_{3}$ in $\mathrm{CNTRL}$ and (c) the difference in $\mathrm{NO}_{3}$ between WSTIR and CNTRL (units of $\mu \mathrm{M}$ ). Ocean interior concentrations $\left(\sigma_{0}=26.8\right)$ are shown averaged over years 2000-2006 for (d) DIC in WSTIR, (e) DIC in CNTRL, and (f) the difference in DIC between WSTIR and CNTRL (units of $\mu$ M).

for the $\mathrm{NO}_{3}$ distributions considered in the same figure. However, the perturbation structure in DIC is markedly different from that seen in $\mathrm{NO}_{3}$. First, the DIC perturbations are as large in the Northern Hemisphere as they are in the Southern Hemisphere for DIC, whereas this is not the case for $\mathrm{NO}_{3}$. Second, for $\mathrm{NO}_{3}$ the perturbations suggest advective propagation, with maxima moving inward from SAMW forma- tion regions in the model. There are more extensive non-local DIC perturbations further from the outcrop region. For both of these tracers, the ocean interior distribution will expect a complex interplay between advection, mixing, and biology, and it is certainly possible that mixing impacts them differently. Another potentially important difference is that gas exchange will impact DIC over the Southern Ocean, but not 
$\mathrm{NO}_{3}$. The complex interplay between these processes, and their impact on the transport of DIC and $\mathrm{NO}_{3}$ northwards from the Southern Ocean, is left as a subject for future investigation.

\section{Discussion}

The sensitivity of contemporary $\mathrm{CO}_{2}$ uptake to a change in wind stirring is significantly larger than the previously reported sensitivity to local wind speed perturbations and gas exchange formulations that impact piston velocity alone (Sarmiento et al., 1992). This is important given the multifaceted role of winds in impacting exchanges of properties across the air-sea interface, as tabulated in the Introduction, and suggests the need to generalize the conceptual model of gas exchange beyond the framework of piston velocities. In fact, not only is the sensitivity found here significantly stronger, but it is also of opposite sign to what is found for surface gas exchange parameterizations, with enhanced wind stirring driving the reduced uptake of contemporary carbon over the Southern Ocean (Fig. 5).

The model revealed a large sensitivity in contemporary carbon uptake over the Southern Ocean not only for a climatological seasonal cycle (seasonal deviations from the annual mean), but also over interannual and longer timescales (Fig. 4). For the seasonal cycle, the CNTRL case exhibits a shift in phase towards earlier spring $\mathrm{CO}_{2}$ uptake relative to WSTIR. This is a consequence of the combined impacts of biology (through light limitation) of the earlier stratification for CNTRL relative to WSTIR, as evidenced in the earlier manifestation of the $\mathrm{Chl}$ concentration maximum for $\mathrm{CN}$ TRL relative to WSTIR (Fig. 7), and the reduced physical entrainment for CNTRL of higher-DIC waters from below.

The sensitivity of Southern Ocean carbon cycling and biogeochemistry to wind stirring should also be expected to have implications for model-derived estimates of the timeevolution of carbon uptake. Interpreting the $0.9 \mathrm{PgC}_{\mathrm{yr}}{ }^{-1}$ difference in integrated air-sea uptake of $\mathrm{CO}_{2}$ over the region to the south of $45^{\circ} \mathrm{S}$ between CNTRL and WSTIR over 2000-2006 as an uncertainty associated with our imperfect knowledge of how to represent wind stirring in models, it is important to consider this uncertainty within the context of the debate waging in the carbon cycle community over whether an ocean carbon-climate feedback is already in evidence in air-sea $\mathrm{CO}_{2}$ fluxes. In fact, this uncertainty identified here is at least of the same order as the global carbon-climate feedback presented in the study of Le Quéré et al. (2007) of $0.2 \pm 0.2 \mathrm{Pg} \mathrm{Cyr}^{-1}$, and the same holds for results presented by Zickfeld et al. (2007) and Lovenduski et al. (2008).

The question arises as to whether the time interval over which we considered the sensitivity to wind stirring (19582006) is of sufficient duration to distinguish between spurious signals associated with adjustments, trends that repre- sent the real response of the system to perturbations, and the longer-term steady-state response of the system. The relatively short duration (several years) of the spurious adjustment signal in Fig. 4 reveals that our interests in both the adjustment period and the long-term steady-state response of the system can be met. The adjustment over decadal timescales is directly pertinent to the type of decadal secular trend in the strength of reanalysis winds over the Southern Ocean as reported by Le Quéré et al. (2007). Such increases in the wind strength (considered in the annual mean and integrated over the Southern Ocean) should be expected to be directly connected to an increase in storminess. Such an increase in the input of high-frequency (less than 10-day) energy from the winds may be expected to contribute to destratifying the planetary boundary layer of the ocean through an increased input of potential energy. This also serves as confirmation of our central hypothesis, namely that by perturbing the transfer of energy from the atmosphere to the ocean, both the steady state and the variability/trends are perturbed.

The strong sensitivity of winter mixed-layer depths to wind stirring (reflected in the green and red lines in Fig. 2d) warrants comment as well. This is scientifically interesting, as it is related to the mechanical forcing provided by the winds and not to heat fluxes or other processes that change sign with the march of the seasons. The deeper mixing in winter for WSTIR relative to CNTRL largely reflects preconditioning or erosion of the stratification below the base of the mixed layer that occurs during summer, with only minimal erosion of stratification occurring through wind stirring in winter given the limited depth scale over which the parameterization is applied. This serves to complement our earlier comments on the impact of wind stirring on the phase of the seasonal cycle of mixed-layer depth. This may help to provide insight not only into mechanisms, but also into the CMIP5 modeled mixed-layer depth biases of the type considered by Sallée et al. (2013).

Finally, it is important to be clear here that forward ocean models such as NEMO or MOM-based models are not by design intended to provide state estimates under reanalysis forcing. Rather, they are better considered as tools for evaluating ocean/climate sensitivity to process-motivated perturbations. Clearly the WSTIR case exhibits biases towards winter mixed-layer depths over the Southern Ocean that are too large. Re-tuning this global $2^{\circ}$ version of NEMO to have both summer and winter mixed-layer depths that better match observations would undoubtedly require an iterative set of experiments where a number of other parameterizations would be tuned, including that for mesoscale eddies. However, the tuning of the circulation and, more generally, the physical state variables does not in itself guarantee an improvement of the model state. The full suite of reanalysis atmospheric fields used to force ocean circulation models are known themselves to suffer from a number of large biases and uncertainties, and these should be expected to contribute to the bias of too-deep mixed-layer depths in the WSTIR 
experiment. The critical point to learn from the results presented here is that the representation of vertical mixing in the model caused important changes in the biogeochemical state from the equilibrium state, demonstrating that our understanding of the dynamical controls on ocean biogeochemistry remains limited.

\section{Conclusions}

The main goal of this study was to investigate the sensitivity of $\mathrm{CO}_{2}$ uptake over the Southern Ocean and, more generally, Southern Ocean biogeochemistry, to an ad hoc parameterization of wind stirring. The ad hoc wind stirring parameterization was developed to account for processes associated with shear-induced turbulence that are commonly unaccounted for in ocean models, whereby summer mixed-layer depths tend to be too shallow over the Southern Ocean and in particular under the maximum westerlies. The ad hoc parameterization, which by construction acts with an e-folding scale depth of $60 \mathrm{~m}$ over the Southern Ocean, was used to tune the NEMO mixed-layer depths to better resemble Argoderived distributions.

The wind stirring parameterization impacts not only the penetration depth of austral summer (DJF) mixed layers, but also the seasonal cycle and phasing of stratification and destratification over the Southern Ocean, particularly in the region of maximum westerlies. With the parameterization, mixed layers remain deeper than $60 \mathrm{~m}$ for 5 weeks longer than without the parameterization in the region between $50^{\circ} \mathrm{S}$ and $60^{\circ} \mathrm{S}$. This has important implications for Southern Ocean carbon cycling, vertical carbon export, Southern Ocean biogeochemistry, and for the injection of preformed nutrients in the ocean interior.

In this study we also sought to evaluate the dynamical controls exerted by ocean mixing processes on atmospheric potential oxygen (APO). Our main scientific finding was that wind stirring exerts a strong control on the phasing of the seasonal cycle of APO, primarily through its impact on the seasonality of air-sea $\mathrm{O}_{2}$ fluxes, with the sensitivity being stronger to the south of the ACC than to the north of the ACC. In the observations we also identified significant year-to-year and intraseasonal variations in the seasonality of APO for Palmer Station. These variations in APO on timescales significantly shorter than the seasonal cycle should be explored mechanistically in a further study. The intraseasonal variations may reflect the response timescales of APO to synopticscale storms, but it is not yet clear to what degree they reflect oceanic and/or atmospheric processes. Give that storminess is expected to increase under 21 st century climate change (Wu et al., 2010), it will be important in future work to identify whether they impact ocean biogeochemistry over large scales.
Increasing wind stirring by including the ad hoc parameterization reduces Southern Ocean $\left(<45^{\circ} \mathrm{S}\right)$ carbon uptake by $0.9 \mathrm{Pg} \mathrm{Cyr}^{-1}$ over years $2000-2006$ relative to the overly stratified control simulation. Wind stirring not only increases summertime mixed-layer depths, thereby impacting light limitation and entrainment of nutrients from below, but it also impacts the phasing of the seasonal cycle and, more generally, biogeochemistry by delaying the timing of re-stratification in spring. Over the Southern Ocean, wind stirring also decreases export production by $0.85 \mathrm{Pg} \mathrm{C} \mathrm{yr}^{-1}$, nearly the same amount by which it reduced ocean uptake of $\mathrm{CO}_{2}$ by gas exchange.

Although inclusion of the ad hoc wind stirring parameterization leads to improvements in the model's physical oceanic state, globally integrated ocean carbon uptake is only $0.1 \mathrm{Pg} \mathrm{Cyr}^{-1}$ over 2000-2006 with the ad hoc parameterization (WSTIR case), much less than the $2.8 \mathrm{PgC} \mathrm{yr}^{-1}$ simulated without the ad hoc parameterization (CNTRL case) over the same period. This latter value obtained without the effect of enhanced wind stirring is, however, in closer agreement with observational estimates of global carbon that are typically between 1.4 and $2.6 \mathrm{Pg} \mathrm{Cyr}^{-1}$ for the 1990-2009 period (Wanninkhof et al., 2013). Importantly, this serves as an example of where biogeochemical models can be tuned to simulate global carbon uptake in agreement with observational products even though their physical circulation states are unsatisfactory. This underscores a potentially very large uncertainty in our ability to model future global carbon uptake.

This study points to the importance of prioritizing process understanding of shear-induced turbulence and its impact on mixed-layer depth over the Southern Ocean and, more generally, over the latitude bands over both hemispheres where storminess may contribute in an important way to the mechanical stirring of the ocean. The mechanistic controls on wind stirring may be expected to include near-inertial oscillations (Jochum et al., 2013) and ocean swells and waves (Qiao et al., 2004; Huang et al., 2012; Huang and Qiao, 2010). It is our hope that the results presented here will serve to further stimulate work in developing process-based parameterizations, with the goal of improving on the ad hoc parameterization applied here. The ad hoc parameterization applied here has been used to tune the physical state of the ocean model under the modern climate state, but of course our WSTIR turning presented here should not be expected to be appropriate for different climate states. Finally, our study suggests that observations of APO could serve a critical role in detecting changes in ocean biogeochemistry and carbon uptake in response to future changes in storminess. 
Acknowledgements. The contribution of K. B. Rodgers came through awards NA17RJ2612 and NA08OAR4320752, which includes support through the NOAA Office of Climate Observations (OCO). The statements, findings, conclusions, and recommendations are those of the authors and do not necessarily reflect the views of NOAA or the US Department of Commerce. Additional support for K. B. Rodgers came through NASA award NNX09AI13G and NSF award OCE-1155983. Support for S. E. Mikaloff Fletcher was provided by NIWA under the New Zealand Greenhouse Gas Emissions, Mitigation, and Carbon Cycle Science Programme. Y. Plancherel acknowledges support from the Oxford Martin School and the UK GEOTRACES Program. Support for measurements of APO ratios was provided under grant NA10OAR4320156, which includes support through the NOAA Climate Program Office. D. Iudicone was funded by the Flagship Project RITMARE - The Italian Research for the Sea - funded by the Italian Ministry of Education, University, and Research within the National Research Program 2011-2013. Y. Plancherel was supported by the Oxford Martin School and UK NERC via the UK GEOTRACES program.

Edited by: L. Cotrim da Cunha

\section{References}

Anav, A., Friedlingstein, P., Kidston, M., Bopp, L., Ciais, P., Cox, P., Jones, C., Jung, M., Myneni, R., and Zhu, Z.: Evaluating the Land and Ocean Components of the Global Carbon Cycle in the CMIP5 Earth System Models, J. Climate, 6, 6801-6843, 2013.

Antonov, J. I., Seldov, D., Boyer, T. P., Locarnini, R. A., Mishonov, A. V., Garcia, H. E., Baranova, O. K., Zweng, M. M., and Johnson, D. R.: World Ocean Atlas 2009, Volume 2: Salinity, in: NOAA Atlas NESDIS 69, edited by: Levitus, S., U.S. Government Printing Office, Washington DC, 184 pp., 2010.

Aumont, O. and Bopp, L: Globalizing results from ocean in situ iron fertilization studies, Global Biogeochem. Cy., 20, GB2017, doi:10.1029/2005GB002591, 2006.

Axell, L. B.: Wind-driven internal waves and Langmuir circulations in a numerical ocean model of the Southern Baltic Sea, J. Geophys. Res., 107, 3204, doi:10.1029/2001JC000922, 2002.

Blanke, B. and Delecluse, P.: Variability of the tropical-Atlantic ocean simulated by a general circulation model with two different mixed-layer physics, J. Phys. Oceanogr., 23, 1363-1388, 1993.

Boden, T. A., Marland, G., and Andres, R. J.: Global, Regional, and National Fossil-Fuel $\mathrm{CO}_{2}$ Emissions, Carbon Dioxide Information Analysis Center, Oak Ridge National Laboratory, U.S. Department of Energy, Oak Ridge, Tenn., USA, doi:10.3334/CDIAC/00001_V2012, 2012.

Bolin, B. and Eriksson, E.: Changes in the carbon dioxide content of the atmosphere and sea due to fossil fuel combustion, in: The Atmosphere and the Sea in Motion: Scientific Contributions to the Rossby Memorial Volume, edited by: Bolin, B., New York, Rockefeller Institute Press, 130-142, 1958

Böning, C., Dispert, A., Visbeck, M., Rintoul, S., and Scharzkopf, F.: The response of the Antarctic Circumpolar Current to recent climate change, Nat. Geosci., 1, 864-869, 2008.
Brodeau, L., Barnier, B., Treguier, A. M., Penduff, T., and Gulev, S.: An ERA40-based atmospheric forcing for global ocean circulation models, Ocean Model., 31, 88-104, doi:10.1016/j.ocemod.2009.10.005, 2010.

Cleveland, R. B., Cleveland, W. S., McRae, J. E., and Terpenning, I.: STL: A Seasonal-Trend Decomposition Procedure Based on Loess, J. Off. Stat., 6, 3-73, 1990.

de Baar, H. J. W., Boyd, P. W., Coale, K. H., Landry, M. R., Tsuda, A., Assmy, P., Bakker, D. C. E., Bozec, Y., Barber, R. T., Brzezinski, M. A., Buesseler, K. O., Boyé, M., Croot, P. L., Gervais, F., Borbunov, M. Y., Harrison, P. J., Hiscock, W. T., Laan, P., Lancelot, C., Law, C. S., Lavasseur, M., Marchetti, A., Millero, F. J., Nishioka, J., Nojiri, Y., van Oijen, T., Riebesell, U., Rijkenberg, M. J. A., Saito, H., Takeda, S., Timmermans, K. R., Veldhuis, M. J. W., Waite, A. M., and Wong, C.-S.: Synthesis of iron fertilization experiments: From the Iron Age in the Age of Enlightenment, J. Geophys. Res., 110, C09S16, doi:10.1029/2004JC002601, 2005.

de Boyer Montégut, C., Madec, G., Fischer, A. S., Lazar, A., and Iudicone, D.: Mixed layer depth over the global ocean: An examination of profile data and a profile-based climatology, J. Geophys. Res., 109, C12003, doi:10.1029/2004JC002378, 2004.

Denning, A. S., Holzer, M., Gurneym, K. R., Heimann, M., Law, R. M., Rayner, P. J., Fung, I. Y., Fan, S.-M., Taguchi, S., Friedlingstein, P., Balkanski, Y., Taylor, J., Maiss, M., and Levin, I.: Threedimensional transport and concentration of $\mathrm{SF}_{6}$ : A model intercomparison study (TransCom 2), Tellus B, 51, 266-297, 1999.

Dong, S., Sprintall, J., Gille, S. T., and Talley, L.: Southern Ocean mixed-layer depth from Argo float profiles, J. Geophys. Res., 113, doi:10.1029/2006JC004051, 2008.

Geider, R. J., MacIntyre, H. L., and Kana, T. M.: A dynamic regulatory model of phytoplanktonic acclimation to light, nutrients, and temperature, Limnol. Oceanogr., 43, 679-694, 1998.

Gent, P. R. and McWilliams, J. C.: Isopycnal mixing in ocean circulation models, J. Phys. Oceanogr., 20, 150-155, 1990.

Gnanadesikan, A.: A simple predictive model for the structure of the oceanic pycnocline, Sciences, 283, 2077-2079, 1999.

Gurney, K. R., Law, R. M., Denning, A. S., Rayner, P. J., Baker, D., Bousquet, P., Bruhwiler, L., Chen, Y.-H., Ciais, P., Fan, S., Fung, I. Y., Gloor, M., Heimann, M., Higuchi, K., John, J., Kowalczyk, E., Maki, T., Maksyutov, S., Peylin, P., Prather, M., Pak, B. C., Sarmiento, J., Taguchi, S., Takahashi, T., and Yuen, C.-W.: TRANSCOM $3 \mathrm{CO}_{2}$ inversion intercomparison: 1. Annual mean control results and sensitivity to transport and prior flux information, Tellus B., 55, 555-579, 2003.

Hallberg, R. and Gnanadesikan, A.: The role of eddies in determining the structure and response of the wind-driven Southern Hemisphere overturning: Results from the Modeling Eddies in the Southern Ocean (MESO) project, J. Phys. Oceanogr., 36, 2232-2252, 2006.

Hamme, R. C. and Keeling, R. F.: Ocean ventilation as a driver of interannual variability in atmospheric potential oxygen, Tellus B, 60, 706-717, 2008.

Heimann, M. and Körner, S.: The global atmospheric tracer model TM3, in: Max-Planck-Institut für Biogeochemie (Eds.): Technical Report, Vol. 5, Max-Planck-Institut für Biogeochemie, Jena, 131 pp., 2003. 
Holte, J. and Talley, L: A new Algorithm for Finding Mixed Layer Depths with Applications to Argo data and Subantarctic Mode Water Formation, J. Atmos. Ocean. Technol., 26, 1920-1939, 2009.

Huang, C. J. and Qiao, F.: Wave-turbulence interaction and its induced mixing in the upper ocean, J. Geophys. Res., 115, C04026, doi:10.1029/2009JC005853, 2010.

Huang, C. J., Qiao, F., Shu, Q., and Song, Z.: Evaluating austral summer mixed-layer response to surface wave-induced mixing in the Southern Ocean, J. Geophys. Res., 117, C00J18, doi:10.1029/2012JC007892, 2012.

Ito, T., Woloszyn, M., and Mazloff, M.: Anthropogenic carbon dioxide transport in the Southern Ocean driven by Ekman flow, Nature, 463, 80-84, 2010.

Jochum, M., Briegleb, B. P., Danabasoglu, G., Large, W. G., Norton, N. J., Jayne, S. R., Alford, M. H., and Bryan, F. O.: The impact of oceanic near-inertial waves on climate, J. Climate, 26, 28332844, 2013.

Kalnay, E., Kanamitsu, M., Kistler, R., Collins, W., Deaven, D., Gandin, L, Iredell, M., Saha, S., White, G., Woollen, J., Zhu, Y., Chelliag, M., Ebisuzaki, W., Higgins, W., Janowiak, J., Mo, K. C., Ropelewski, C., Wang, J., Leetma, A., Reynolds, R., Jenne, R., and Joseph, D.: The NCEP/NCAR reanalysis project, B. Am. Meteor. Soc., 77, 437-471, 1996.

Keeling, R. F.: Measuring correlations between atmospheric oxygen and carbon dioxide mole fractions: A preliminary study in urban air, J. Atmos. Chem., 7, 153-176, 1998.

Keeling, R. F. and Maning, A. C.: Studies of Recent Changes in Atmospheric $\mathrm{O}_{2}$ Content, in: Treatise on Geochemistry, Vol. 4, edited by: Keeling, R. F. and Russell, L., Amsterdam, Elsevier, 385-404, 2013.

Keeling, R. F. and Peng, T.-H.: Transport of heat, $\mathrm{CO}_{2}$, and $\mathrm{O}_{2}$ by the Atlantic's thermohaline circulation, Philos. T. R. Soc. B, 348, 133-142, 1995.

Keeling, R. F. and Shertz, S. R.: Seasonal and interannual variations in atmospheric oxygen and implications for the global carbon cycle, Nature, 358, 723-727, 1992.

Lenton, A., Tilbrook, B., Law, R., Bakker, D., Doney, S. C., Gruber, N., Hoppema, M., Ishii, M., Lovenduski, N. S., Matear, R. J., McNeil, B. I. Metzl, N., Mikaloff Fletcher, S. E., Monteiro, P., Rödenbeck, C., Sweeney, C., and Takahashi, T.: Sea-air $\mathrm{CO}_{2}$ fluxes in the Southern Ocean for the period 1990-2009, Biogeosciences, 10, 4037-4054, doi:10.5194/bg-10-4037-2013, 2013.

Le Quéré, C., Rödenbeck, C., Buitenhuis, E. T., Conway, T. J., Langenfelds, R., Gomez, A., Labuschagne, C., Ramonet, M., Nakazawa, T., Metzl, N., Gillett, N., and Heimann, M.: Saturation of the Southern Ocean $\mathrm{CO}_{2}$ sink due to recent climate change, Science, 316, 1735-1738, 2007.

Li, Q. P., Franks, P. J. S., Landry, M. R., Goericke, R., and Taylor, A. G.: Modeling phytoplankton growth rates and chlorophyll to carbon ratios in California coastal and pelagic ecosystems, J. Geophys. Res., 115, G04003, doi:10.1029/2009JG001111, 2010.

Locarnini, R. A., Mishonov, A. V., Antonov, J. I., Boyer, T. P., Garcia, H. E., Baranova, O. K., Zweng, M. M., and Johnson, D. R.: World Ocean Atlas 2009, Volume 1: Temperature, in: NOAA Atlas NESDIS 68, edited by: Levitus, S., U.S. Government Printing Office, Washington DC, 184 pp., 2010.
Lovenduski, N, Gruber, N., and Doney, S. C.: Towards a mechanistic understanding of the decadal trends in the Southern Ocean carbon sink, Global Biogeochem. Cy., 22, GB3016, doi:10.1029/2007GB003139, 2008.

Madec, G., Delecluse, P., Imbard, M., and Levy, C.: OPA 8.1 general circulation model reference manual, in Notes du Pole de Modelisation de l'Institut Pierre-Simon Laplace, 11, 91 pp., available at: http://www.lodyc.jussieu.fr/opa, 1998.

Marinov, I., Gnanadesikan, A., Toggweiler, J. R., and Sarmiento, J. L.: The Southern Ocean biogeochemical divide, Nature, 441, 964-967, 2006.

Marland, G., Andres, R. J., Boden, T. A., and Johnston, C.: Global, regional and national $\mathrm{CO}_{2}$ emission estimates from fossil fuel burning, cement production, and gas flaring: 1751-1995 (revised January 1998), ORNL/CDIAC NDP-030/R8, http://cdiac. esd.ornl.gov/ndps/ndp030.html, 1998.

Marland, G., Boden, T., and Andres, R.: Global, regional and national $\mathrm{CO}_{2}$ emissions, in Trends: A compendium of Data on Global Change, Carbon Dioxide Inf. Anal. Cent., Oak Ridge Natl. Lab., U.S. Dep. of Energy, Oak Ridge, Tenn., 2003.

Mignone, B. K., Gnanadesikan, A., Sarmiento, J. L., and Slater, R. D.: Central role of Southern Hemisphere winds and eddies in modulating the oceanic uptake of anthropogenic carbon, Geophys. Res. Lett., 33, L01604, doi:10.1029/2005GL024464, 2006.

Qiao, F., Yuan, Y., Yang, Y., Zheng, Q., Xia, C., and Ma, J.: Waveinduced mixing in the upper ocean: Distribution and application to a global ocean circulation model, Geophys. Res. Lett., 31, L11303, doi:10.1029/2004GL019824, 2004.

Reynolds, R. W. and Smith, T. M.: Improved global sea surface temperature analyses, J. Climate, 7, 929-948, 1994.

Rodgers, K. B., Blanke, B., Madec, G., Aumont, O., Ciais, P., and Dutay, J. C.: Extratropical Sources of Equatorial Pacific Upwelling in an OGCM, Geophys. Res. Lett., 30, 1084, doi:10.1029/2002GL016003, 2003.

Roemmich, D. and Gilson, J.: The 2004-2007 mean and annual cycle of temperature, salinity, and steric height in the global ocean from the Argo Program, Progr. Oceanogr., 82, 81-100, doi:10.1016/j.pocean.2009.03.004, 2009.

Sallée, J.-B., Shuckburgh, E., Bruneau, N., Jeijers, A. J. S., Bracegirdle, T. J., and Wang, Z.: Assessment of Southern Ocean mixed-layer depths in CMIP5 models: Historical bias and forcing responses, J. Geophys. Res. Ocean., 118, 1845-1862, 2013.

Sarmiento, J. L, Orr, J. C., and Sigenthaler, U.: A perturbation simulation of $\mathrm{CO}_{2}$ uptake in an ocean general circulation model, J. Geophys. Res., 97, 3621-3645, 1992.

Sarmiento, J. L., Gruber, N., Brzezinski, M. A., and Dunne, J. P.: High latitude controls of thermocline nutrients and low latitude productivity, Nature, 427, 56-60, 2004.

Severinghaus, P., Grachev, A., and Battle, M.: Thermal fractionation of air in polar firn by seasonal temperature gradients, Geochem. Geophy. Geosy., 2,1048, doi:10.1029/2000GC000146, 2001.

Stephens, B. B., Keeling, R. F., Heimann, M., Six, K. D., Murnane, R., and Caldeira, K.: Testing global ocean carbon cycle models using measurements of atmospheric $\mathrm{O}_{2}$ and $\mathrm{CO}_{2}$ concentration, Global Biogeochem. Cy., 12, 213-230, 1998.

Stephens, B. B., Gurney, K. R., Tans, P. P., Sweeney, C., Peters, W., Bruhwiler, L, Ciais, P., Ramonet, M., Bousquet, P., Nakazawa, T., Aoki, S., Machida, T., Inoue, G., Vinnichenko, N., Lloyd, J., Jordan, A., Heimann, M., Shibistova, O., Langen- 
felds, R. L., Steele, L. P., Francey, R. J., and Denning, A. S.: Weak northern and strong tropical land carbon uptake from vertical profiles of atmospheric $\mathrm{CO}_{2}$, Sciences, 316, 1732-1735, doi:10.1126/science.1137004, 2007.

Stephens, B. B., Brailsford, G. W., Gomez, A. J., Riedel, K., Mikaloff Fletcher, S. E., Nichol, S., and Manning, M.: Analysis of a 39-year continuous atmospheric $\mathrm{CO}_{2}$ record from Baring Head, New Zealand, Biogeosciences, 10, 2683-2697, doi:10.5194/bg-10-2683-2013, 2013.

Stommel, H.: Determination of watermass properties of water pumped down from the Ekman layer to the geostrophic flow below, P. Natl. Acad. Sci. USA, 76, 3051-3055, 1979.

Strzepek, R. F., Hunter, K. A., Frew, R. D., Harrison, P. J., and Boyd, P. W.: Iron-light interactions differ in Southern Ocean phytoplankton, Limnol. Oceanogr., 57, 1182-1200, 2012.

Takahashi, T., Sutherland, S. C., Wanninkhof, R., Sweeney, C., Feely, R. A., Chipman, D. W., Hales, B., Friederich, G., Chavez, F., Sabine, C., Watson, A., Bakker, D. C. E., Schuster, U., Metzl, N., Yoshikawa-Inoue, H., Ishii, M., Midorikawa, T., Nojiri, Y., Kortzinger, A., Steinhofff, T., Ishii, M., Midorikawa, T., Nojiri, Y., Körtzinger, A., Steinhoff, T., Hoppema, M., Olafsson, J., Arnarson, T. S., Tilbrook, B., Johannessen, T., Olsen, A., Bellerby, R., Wong, C. S., Delille, B., Bates, N. R., and de Baar, H. J. W: Climatological mean and decadal change in surface ocean $p \mathrm{CO}_{2}$, and net sea-air $\mathrm{CO}_{2}$ flux over the global oceans, Deep-Sea Res. Pt. II 56, 554-577, 2009.

Toggweiler, J. R. and Samuels, B.: New radiocarbon constraints on the upwelling of abyssal water to the ocean's surface, in: the Global Carbon Cycle, edited by: Heimann, M., NATO ASI Ser. I, 15, 333-336, 1993.
Uppala, S. M., Kallberg, P. W., Simmons, A. J., Andrae, U., da Costa Bechtold, V., Fiorino, M., Gibson, J. K., Haseler, J., Hernandez, A., Kelly, G. A., Li, X., Onogi, K., Saarinen, S., Sokka N., Allan, R. P., Andersson, E., Arpe, K., Balmaseda, M. A., Beljaars, A. C. M., van de Berg, L., Bidlot, J., Bormann, N., Caires, S., Chevallier, F., Dethof, A., Dragosavac, M., Fisher, M., Fuentes, M., Hagemann, S., Holm, E., Hoskins, B. J., Isaksen, L., Janssen, P. A. E. M., Jenne, R., McNally, A. P., Mahfouf, J.-F., Morcrette, J.-J., Rayner, N. A., Saunders, R. W., Simon, P., Sterl, A., Trenberth, K. E., Untch, A., Vasiljevic, D., Viterbo, P., and Woollen, J.: The ERA-40 re-analysis, Q. J. R. Meteorol. Soc., 131, 2961-3012, doi:10.1256/qj.04.176, 2005.

Wanninkhof, R.: Relationship between wind speed and gas exchange over the ocean, J. Geophys. Res., 97, 7373-7382, 1992.

Wanninkhof, R., Asher, W. E., Ho, D. T., Sweeney, C., and McGillis, W. R.: Advances in quantifying air-sea gas exchange and environmental forcing, Annu. Rev. Mar. Sci., 1, 213-244, 2009.

Wanninkhof, R., Park, G.-H., Takahashi, T., Sweeney, C., Feely, R., Nojiri, Y., Gruber, N., Doney, S. C., McKinley, G. A., Lenton, A., Le Quéré, C., Heinze, C., Schwinger, J., Graven, H., and Khatiwala, S.: Global ocean carbon uptake: magnitude, variability and trends, Biogeosciences, 10, 1983-2000, doi:10.5194/bg10-1983-2013, 2013.

Weiss, R. F.: The solubility of nitrogen, oxygen and argon in water and seawater, Deep-Sea Res., 17, 721-735, 1970.

Wu, Y., Ting, M., Seager, R., Huange, H.-P., and Cane, M. A.: Changes in storm tracks and energy transports in a warmer climate simulated by the GFDL CM2.1 model, Clim. Dynam., 37, 53-72, doi:10.1007/s00382-010-0776-4, 2010.

Wyrtki, K.: The thermohaline circulation in relation to the general circulation in the oceans, Deep-Sea Res., 8, 39-64, 1961.

Zickfeld, K., Fyfe, J. C., Saenko, O. A., Eby, M., and Weaver, A. J.: Response of the global carbon cycle to human-induced changes in Southern Hemisphere winds, Geophys. Res. Lett., 34, L12712, doi:10.1029/2006GL028797, 2007. 